Revista de Ciencias Sociales - Número 62 (2013) - Páginas 13-37
Hans Kelsen: vida y obra

\title{
HANS KELSEN: VIDA Y OBRA
}

\author{
GREGORIO ROBLES MORCHÓN* \\ Universidad de las Islas Baleares, España \\ gregoriorobles@yahoo.es
}

\section{Los escritos autobiográficos de Hans Kelsen}

Con ocasión del 125 Aniversario del nacimiento del gran jurista Hans Kelsen, se anunció en el Parlamento de Viena, en una sesión en su memoria, la publicación de sus obras completas en una edición crítica $^{1}$. En la misma sesión los organizadores — dirigidos por el profesor Matthias Jestaedt - repartieron un pequeño volumen en el cual se contienen dos escritos autobiográficos de Kelsen, uno con fecha de 1927, y el segundo, con data de veinte años después, $1947^{2}$. Es, pues, un buen

* $\quad$ Catedrático de Filosofía del Derecho.

1. Las obras completas de Hans Kelsen comenzaron a publicarse en el año 2007 por la Editorial Mohr Siebeck (Tübingen, Alemania), con el título Hans Kelsen Werke, siendo editores y coordinadores el profesor Matthias Jestaedt (entonces en Erlangen, ahora en Freiburg im Breisgau) en cooperación con el Instituto Hans Kelsen de Viena.

2. Hans Kelsen im Selbstzeugnis. Sonderpublikation anlässlich des 125. Geburtstages von Hans Kelsen am 11. Oktober 2006, editado por Matthias Jestaedt en cooperación con el Instituto Hans Kelsen, Mohr Siebeck, Tübingen, 2006. Junto a los escritos autobiográficos, este volumen contiene, además de un prefacio de Robert Walter y Clemens Jabloner — a la sazón directores del Instituto Hans Kelsen — y de un prólogo

Revista de Ciencias Sociales - Número 62 (2013) - Universidad de Valparáíso - ISSN 0716-7725-Valparaíso, Chile 
momento para, a la luz de estos escritos y teniendo en cuenta la única biografía que hasta el momento existe sobre Kelsen, escrita por Rudolf A. Métall, sintetizar la vida del ilustre maestro de la llamada Escuela de Viena de Teoría del Derecho. Pero antes digamos algo sobre el carácter y el estilo de los dos escritos autobiográficos y asimismo sobre la biografía de Métall ${ }^{3}$.

El escrito de 1927 se titula "Selbstdarstellung", que puede traducirse como "autoexposición". Se trata de unos ocho folios escritos, según relata la carta adjunta, escrita por la mujer de Kelsen, Margarette, debido a que el maestro tenía una herida en una mano. Al parecer, este escrito fue elaborado a petición de Julios Moor $^{4}$, un filósofo del derecho húngaro que había traducido el Compendio de Teoría del Estado y que, por la razón que fuera — posiblemente para hacer la presentación del libro- pidió a Kelsen unas referencias sobre su trayectoria. Este escrito

de Matthias Jestaedt, una Introducción de este último sobre los caracteres y la intrahistoria de los mencionados escritos. Al final del libro se presenta un cuadro cronológico que refleja los datos profesionales así como sus obras más importantes. Y, por último, aparecen una serie de fotografías de los familiares de Kelsen y de él mismo en las diversas fases de su vida. Todo este conjunto de elementos se recogen asimismo en el volumen I de las Obras Completas, que además comprende los trabajos de Kelsen publicados entre 1905 y 1910. Hay traducción al español del pequeño volumen autobiográfico, con sus estudios previos: Hans Kelsen, Autobiografía, Traducción y Presentación: Luis Villar Borda, en cooperación con el Instituto Hans Kelsen, Universidad Externado de Colombia, Bogotá, 2008.

3. Rudolf Aladár Métall, Hans Kelsen. Leben und Werk, Wien, 1969. Hay traducción al español de Javier Esquivel.

4. Julios Moor (1888-1950), iusfilósofo húngaro muy conocido en la época.

5. Kelsen había publicado en 1925 su gran tratado de Teoría general del Estado, Allgemeine Staatslehre, Editorial Julios Springer, Berlin. Para facilitar el estudio se imprimió el Compendio como impresión privada: Grundriss einer allgemeinen Theorie des Staates, Viena 1926. Moor lo tradujo al húngaro y se publicó en 1927. En España los tradujeron Luis Recaséns Siches y Justino de Azcárate, primero con el título Compendio esquemático de Teoría General del Estado, con Introducción de Luis Recaséns Siches, Barcelona, Núñez y Comp., 1928. Más tarde con el título Compendio de Teoría General del Estado, Editorial Bosch, Barcelona, 1934.

Facultad de Derecho y Ciencias Sociales - Universidad de Valparaíso - Chile 
se limita a relatar los aspectos más destacados de la carrera académica de Kelsen y el significado de algunas de sus obras. Se trata, en suma, de una especie de currículum vitae, en el que no se reflejan aspectos personales.

De esto último hay algo más —aunque siempre en relación directa con la vida académica - en el segundo escrito, el de 1947, titulado justamente "Autobiographie". Si el anterior fue redactado cuando Kelsen vivía en Viena, éste pertenece a la época en que ya se encontraba asentado en la Universidad de Berkeley, California. La ocasión la propició el ruego de un historiador norteamericano, llamado Charles Adams Gulick (1896-1984), con objeto de utilizarlo para una obra sobre la historia de Austria que se publicó en $1948^{6}$. El estilo de este escrito es más bien objetivo, descriptivo de acontecimientos y situaciones, sin entrar demasiado en valoraciones personales, salvo en algún caso especial, como tendremos ocasión de ver enseguida.

Llama la atención el hecho de que Kelsen, que murió en 1973, esto es, casi treinta años después de su "Autobiografía" no haya proporcionado un escrito equivalente para sus años californianos. Quizás la razón haya que encontrarla en que a partir de que se estableciera en Berkeley cambió su vida azarosa y entró a formar parte de los privilegiados que ven desde su casa el Océano Pacífico y pueden dedicar sus días tranquilos al estudio y a la creación intelectual. Esto parece indicar las palabras con las que da fin a su "Autobiografía": "Während der Niederschrift dieser Erinnerungen habe ich das 66. Lebensjahr erreicht. Durch das breite Fenster, an dem mein Schreibtisch steht, blicke ich über Gärten hinweg auf die Bay von San Francisco und die Golden Gate Brücke, hinter der der Pazifische Ozean glänzt. Hier wird wohl des 'Wandermüden letzte Ruhestätte' sein. Oktober, 1947". Esto es: "Durante estos días, dedicados a escribir los recuerdos aquí recogidos, he alcanzado mi sexagésimo sexto cumpleaños. A través del amplio ventanal que está frente a mi mesa de escritorio puedo divisar, allende los jardines, la bahía de San Francisco y el puente del Golden Gate, tras el cual resplandece el Océano Pacífico. Seguro que éste será

6. Charles A. Gulick, Austria from Habsburg to Hitler, 2 vols., Berkeley \& Los Angeles, 1948.

Revista de Ciencias Sociales - Número 62 (2013) - Universidad de Valparáíso - ISSN 0716-7725-Valparaíso, Chile 
'el definitivo refugio de solaz para el fatigado caminante'. Octubre, 1947 "'.

La única biografía sobre Kelsen tiene por autor, como ya se ha dicho, a Rudolf A. Métall (1903-1975). Originariamente austriaco, emigró a Brasil en 1940 y adquirió la nacionalidad brasileña. Discípulo de Kelsen, se doctoró en Viena en 1925 y fue su asistente en la Universidad. Su colaboración con el maestro se prolongó a lo largo del tiempo durante toda la vida ${ }^{8}$. La biografía está construida en gran parte sobre los dos escritos autobiográficos de Kelsen (prácticamente las tres cuartas partes del libro, dedicadas a las fases de la vida de Kelsen anteriores a su llegada a Estados Unidos). Además, por las propias vivencias personales y por el trato y las conversaciones que mantuvo siempre con el maestro vienés.

\section{Nacimiento, infancia y primera juventud}

Hans Kelsen nació en Praga el 11 de octubre de 1881 en el seno de una familia judía. Su padre, Adolf Kelsen ${ }^{9}$, provenía de Galizien, y

7. Hans Kelsen in Selbszeugnis, citado, p. 94, La cita "el definitivo refugio de solaz para el fatigado caminante" es un verso de una poesía que figura en el epitafio de la tumba de Heinrich Heines (1797-1856) en el cementerio de Montmartre de París.

8. Métall no fue sólo asistente de Kelsen, sino también amigo personal. De 1928

a 1935 fue secretario de redacción de la Zeitschrift für öffentliches Recht, de la que Kelsen fue director hasta 1934, y de 1933 a 1940 ocupó un cargo similar en la Revue internationale de la théorie de droit, cuyos directores eran Hans Kelsen, Léon Duguit y Franz Weyr. En 1931 entró al servicio del Bureau Internacional de Travail, en Ginebra (en el año 1933 Kelsen llegará a Ginebra procedente de Colonia, y en esa ciudad permanecerá hasta 1940, cuando emigra a los EEUU, mientras que Métall emigró al Brasil. De 1940 a 1945 Métall fue asesor del gobierno brasileño, y a partir de 1946 ocupó un puesto en Nueva York en la Organización Internacional de Trabajo, a partir de 1959 de nuevo en Ginebra. Su contacto con Kelsen fue constante, y éste le nombró albacea, de tal modo que su legado científico pasó a su muerte a manos de Métall, el cual a su vez lo legó al Instituto Hans Kelsen de Viena. Vide HKW (Hans Kelsen Werke), vol. I, p. 78.

9. Adolf Kelsen (1850-1907), nació en Brody, Galizien, ciudad que hoy pertenece a Ucrania. Brody era una urbe con gran población judía. Murió en Viena.

Facultad de Derecho y Ciencias Sociales - Universidad de Valparaíso - Chile 
era propietario de una pequeña fábrica de lámparas. Su madre ${ }^{10}$ provenía de Bohemia. El matrimonio tuvo cuatro hijos, el mayor de los cuales era Hans ${ }^{11}$. Cuando éste apenas contaba tres años, la familia se trasladó a Viena ${ }^{12}$. Por tanto, aunque Kelsen no había nacido en esta ciudad, siempre se consideró "un vienés", con lo que eso implicaba en aquella época en que Viena era la capital política y cultural del gran Imperio austro-húngaro. En Viena transcurrió la vida de Kelsen hasta el año 1930, cuando acudió a la llamada de la Universidad de Colonia.

En el Gymnasium no destacó como estudiante. Sin embargo, ya apuntaba inquietudes intelectuales en cuanto que le atraía la literatura y, sobre todo, la física y las matemáticas. Su decisión por estudiar en la Facultad de Derecho se debió más que a otra cosa a motivaciones de índole pragmática. En 1901 comienza sus estudios universitarios que culmina en 1906, con la obtención del título de doctor.

El paso por la Facultad de Derecho constituyó para el joven Kelsen una gran decepción. En aquel entonces los estudios jurídicos en la Universidad de Viena, en la denominada "Alma Mater Rudolphina”, se dividían en dos ciclos. En el primero se estudiaba la historia del derecho en sus diversas ramas: historia del derecho romano, del derecho germánico, del derecho austriaco. El segundo ciclo estaba centrado en las disciplinas explicativas del derecho vigente en Austria, disciplinas propiamente dogmáticas. La decepción que el joven Kelsen experimentó en la Facultad se debió a que no encontró en ella una ciencia jurídica asentada sobre un método riguroso. Muy al contrario, las diversas disciplinas se caracterizaban por mezclar los enfoques. Los docentes las exponían en sus clases y en sus libros entremezclando razonamientos de todo tipo: junto a los normativos o jurídicos, los históricos, los sociológicos, los económicos, los filosóficos y teológicos e

10. Auguste Kelsen (de soltera, Löwy) (1858-1950) nació en Neuhaus (Böhmen), actualmente República Checa. Auguste murió en Bled (Yugoslavia).

11. Los tres hermanos de Hans Kelsen fueron: Ernst (Praga 1883-Londres 1937); Gertrude (Viena 1886-Hertford, Reino Unido, 1951); Paul Friedrich (Viena 1897-Viena 1975).

12. Eso ocurrió en el año 1884.

Revista de Ciencias Sociales - Número 62 (2013) - Universidad de Valparáíso - ISSN 0716-7725-Valparaíso, Chile 
incluso los biológicos. A Kelsen le pareció que una verdadera ciencia del derecho, autónoma en cuanto a su objeto y a su método, brillaba por su ausencia. Esta percepción en edad juvenil marcará definitivamente sus obras a lo largo de toda su vida, pues — como veremos enseguida - su propósito no fue otro que encontrar la senda para la construcción de una ciencia del derecho que estuviese a la altura de las demás ciencias, esto es, con objeto y método propios.

Le defraudaron en general los profesores por la razón mencionada y porque no despertaban el entusiasmo que él había esperado. Tan sólo exceptuó a dos de ellos: a Edmund Bernatzik y a Leo Strisower. Bernatzik (1854-1919) ${ }^{13}$ era catedrático de Derecho político y constitucional y se caracterizaba, según Kelsen, no por su laboriosidad, sino por la agudeza de su inteligencia. Sus clases, dedicadas al análisis crítico de la Constitución austriaca y, en general, del Derecho público austriaco, atraían a multitud estudiantes de otras Facultades, pues sus explicaciones estaban adornadas siempre de gran ingenio y humor e incluso a veces de sarcasmo. El segundo profesor cuya docencia atrajo al Kelsen estudiante fue Leo Strisower (1857-1931), profesor de Derecho internacional y de Filosofía del Derecho ${ }^{14}$. Fue en las clases de Historia de la Filosofía del Derecho de este profesor, que en palabras del propio Kelsen, eran las únicas a las que asistía con regularidad, donde se enteró de que el poeta Dante Alighieri era autor de un importante libro de Filosofía Política, titulado De Monarchia.

Comenta Kelsen en su "Autobiografía" que se planteó enseguida la posibilidad de hacer un trabajo sobre las concepciones políticas y jurídicas del Dante. Le consultó sobre esa posibilidad a Strisower, quien, para decepción del joven, le aconsejó que era mejor que se dedicara a estudiar bien las asignaturas de la carrera, ya que —entre otros posibles argumentos - sobre el poeta florentino se había escrito y publicado

13. Edmund Bernatzik había sido profesor en Basilea, en Graz, y desde 1894 hasta su muerte en 1919 lo fue en la Universidad de Viena. Sus clases no se redujeron al Derecho constitucional, también impartió docencia de Derecho administrativo.

14. Leo Strisower llegó a ser presidente del Institut de Droit Internacional. Fue también miembro del Curatorium de la Academia de La Haya.

Facultad de Derecho y Ciencias Sociales - Universidad de Valparaíso - Chile 
todo lo que uno pudiese imaginar. Hay que convenir con Strisower que la elaboración de un trabajo algo serio sobre Dante no era quizás la mejor opción para un estudiante que no acababa de encontrar el gusto por los estudios jurídicos y que, en ese aspecto, más podía parecer una "huida hacia delante" y a la postre puede ser que también una pérdida de tiempo. El caso, sin embargo, es que el joven Kelsen no siguió el consejo de su profesor de Historia de la Filosofía del Derecho. Su razonamiento no deja de ser aceptable, al tiempo que demuestra ya el carácter de quien acabaría siendo un jurista eminente. Viene a decir Kelsen en su "Autobiografía" que se decidió por hacer el trabajo mencionado aunque sólo fuera por encontrar una tarea concreta que, sin salirse de los estudios propios de la Facultad, le incentivara lo suficiente como para superar la apatía que le provocaban las disciplinas jurídicas en general.

Así es como Kelsen escribió su primer libro: Die Staatslehre des Dante Alighieri. Lo publicó en el año 1905, siendo aún estudiante, en una colección de monografías que dirigía Edmund Bernatzik ${ }^{15}$. Se trata de un pulcro trabajo sin otra pretensión que hacer un resumen comentado de las ideas políticas de Dante, apoyado en abundante bibliografía secundaria. Algunas veces se ha sostenido que este estudio constituía la Dissertation de Kelsen, esto es, su trabajo de tesis doctoral. Pero esto no es cierto. En aquella época se adquiría el título de doctor por medio de la realización de varios exámenes ${ }^{16}$.

$\mathrm{Al}$ concluir sus estudios en la Facultad de Derecho, Kelsen se plantea la posibilidad de habilitarse para la docencia universitaria, para lo cual se entrevista con Edmund Bernatzik. Éste le desaconseja embarcarse en la carrera docente y le sugiere que se prepare para la judicatura o la abogacía. Le viene a decir al joven Kelsen que su

15. Hans Kelsen, Die Staatslehre des Dante Alighieri, Franz Deuticke, Wien und Leipzig, 1905 (Wiener Staatswissenschaftliche Studien von Edmund Bernatzik und Eugen von Philippovich in Wien, Sechster Band, Drittes Heft). Actualmente en el volumen I de las Obras Completas (HKW), pp. 135 y ss.

16. En concreto — según me informa el Dr. Zeleny (Viena) — los exámenes eran: tres exámenes de Estado y tres rigorosa (exámenes para obtener el título de doctor).

Revista de Ciencias Sociales - Número 62 (2013) - Universidad de Valparáíso - ISSN 0716-7725-Valparaíso, Chile 
condición de judío le puede complicar las cosas en la carrera académica, habida cuenta de la situación en este aspecto de la Universidad de Viena, en la cual había ya un número notable de profesores de origen judío, lo cual provocaba un cierto malestar en el resto del cuerpo docente. Hay que suponer, además, que en la sociedad vienesa se respiraba, en ciertos ambientes, un grado relativamente alto de aversión hacia los judíos.

Estos primeros años posteriores a sus estudios en la Universidad van a ser algo difíciles para Kelsen pero, al mismo tiempo, van a constituir un período muy ilusionado de su vida. Lo primero, porque - como hermano mayor - tiene que contribuir a los gastos de su familia, ya que el negocio de su padre atraviesa una situación difícil. Ejerce como abogado y compagina el ejercicio de la abogacía con la docencia. La situación económica se agrava en cuanto muere su padre en 1907. A pesar de esas dificultades, Kelsen se decide por embarcarse en el trabajo de habilitación, para lo cual planea una estancia en Heidelberg, bajo la dirección de Georg Jellinek, a la sazón indiscutible maestro del Derecho público en los países de habla alemana. Las dificultades no fueron pocas: por dos veces se le niega una beca, pero a la tercera petición consigue su propósito. De 1908 a 1910 pasará varios semestres en Heidelberg y en Berlín, asistiendo a los seminarios de Georg Jellinek y de Gerhard Anschütz, otro gran tratadista del Derecho público alemán. Esas estancias tuvieron que interrumpirse periódicamente con el objeto de volver a Viena para ayudar económicamente a su familia. No cabe ninguna duda de que, a pesar de esos obstáculos, Kelsen supo aprovechar el tiempo al máximo, a juzgar por el volumen y el rigor de su trabajo de habilitación. Además, según él mismo declara, fueron unos años muy felices, pues la sensación de abrirse camino a través de la selva de autores y doctrinas de la Teoría general del Derecho, encontrando su propia vía, constituyó para él un inmenso placer intelectual, a la par que una intensa experiencia vital.

Georg Jellinek había nacido en 1851 en la ciudad de Leipzig (Alemania), pero seis años después se trasladó a Viena con sus padres. Parte de sus estudios universitarios los realizó en esa ciudad (también en Heidelberg y en Leipzig). En Leipzig se doctoró en Filosofía en 1872 con un estudio sobre la concepción del mundo de Leibniz y Schopenhauer; y en Viena se doctoró en Derecho en 1874. Obtuvo

Facultad de Derecho y Ciencias Sociales - Universidad de Valparaíso - Chile 
primero la venia legendi para Filosofía del Derecho (1879), y más tarde para Derecho internacional y Derecho público (1882). De 1883 a 1889 ejerce la docencia en la Universidad de Viena como profesor extraordinario (ausserordentlicher Professor). Antes las dificultades para obtener una plaza de profesor ordinario, debido en gran parte a la campaña contra la "judaización" en la Universidad de Viena, renuncia a su puesto. Un año después es nombrado ordinario en la Universidad de Basilea (Suiza) (1890), y al año siguiente en la de Heidelberg (Alemania), donde enseñaría Derecho político general (Allgemeines Staatsrecht) y Derecho internacional (Völkerrecht). De 1891 a 1911, año de su muerte, ejercería su docencia en esta última Universidad. Georg Jellinek llegó a ser el teórico del Estado y del Derecho público con mayor prestigio de la época. Junto a otras obras importantísimas, destacan - por el enorme influjo ejercido en la teoría alemana del Derecho público — su tratado sobre Teoría del Estado ${ }^{17}$ y su monografía sobre los derechos públicos subjetivos ${ }^{18}$. En España se tradujo la primera, y también disponemos de un opúsculo titulado Fragmentos de Estado ${ }^{19}$.

Cuando Kelsen asistió a los seminarios de Jellinek, se encontraba éste en la cúspide de su carrera y en el momento de mayor madurez de su obra. Lamentablemente murió con 60 años de edad, lo que supuso sin duda alguna una gran pérdida para la ciencia jurídica. Las relaciones de Kelsen con Jellinek no llegaron a ser fluidas. Según la versión del primero, el maestro de Heidelberg no estaba acostumbrado a las críticas, antes al contrario, los halagos de sus discípulos le tenían rodeado de una atmósfera excesivamente complaciente. A pesar de esa circunstancia,

17. Georg Jellinek, Allgemeine Staatslehre, Berlin, 1900; tercera edición, Berlín, 1914. Hay traducción española de la segunda edición alemana de Fernando de los Ríos con prólogo de este autor: Teoría General del Estado, Ed. Albatros, Buenos Aires 1970.

18. Georg Jellinek, System der subjektiven öffentlichen Rechte, Freiburg im Breisgau 1892; segunda edición, Tübingen 1905.

19. Georg Jellinek, Über Staatsfragmente, Heidelberg, Fragmentos de Estado, Traducción de Michael Forster, Miguel Herrero de Miñón y José Carlos Esteban, Introducción de Miguel Herrero de Miñón. Editorial Civitas, Madrid 1981.

Revista de Ciencias Sociales - Número 62 (2013) - Universidad de Valparáíso - ISSN 0716-7725-Valparaíso, Chile 
Kelsen siempre consideró a Jellinek como su maestro ${ }^{20}$, además de cómo un gran teórico del Derecho político y del Derecho público.

A juzgar por lo que después publicaría Kelsen, puede deducirse que las críticas que éste manifestó a las posiciones de Jellinek iban dirigidas, sobre todo, a su concepción de las "dos caras" del Estado. Jellinek defiende la tesis de que el Estado puede ser considerado como fenómeno jurídico y como fenómeno social, y que, en consecuencia es posible compatibilizar una teoría jurídica del Estado con una teoría social del Estado. Esta tesis no la acepta Kelsen, por considerar que el Estado es simplemente el Derecho y que, por tanto, no cabe una teoría social, sino meramente jurídica. Sobre este aspecto volveremos después.

\section{El trabajo de habilitación: Hauptprobleme}

Kelsen se habilitó en 1911 con un amplio estudio titulado Hauptprobleme der Staatsrechtslehre entwickelt aus der Lehre vom Rechtssatze 21 ("Problemas capitales de la Teoría del Derecho del Estado"22, a partir de la teoría de la proposición jurídica"23). Se le habilitó para la docencia de "Derecho del Estado" (Derecho político) y Filosofía del Derecho.

El mismo año moría Georg Jellinek. Kelsen se refiere a él en el Prólogo en unos términos muy laudatorios. Dice así: "Mientras las últimas galeradas de este trabajo iban a la imprenta, moría en Heidelberg

20. En el Prólogo de su Teoría General del Estado (1925, trad. de Legaz, 1934), Kelsen se refiere a Jellinek como "mi inolvidable maestro" (p. IX).

21. Editorial J.C.B. Mohr, Tübingen 1911.

22. Staatsrecht es la denominación de lo que en España, siguiendo la terminología francesa, se ha conocido con el nombre de "Derecho político". Esta denominación ha caído algo en desuso, por lo que puede sr conveniente sustituirla por otra como la de "Derecho del Estado" que, sin embargo tampoco es completamente satisfactoria. La designación Staatsrechtslehre viene a ser equivalente a Allgemeine Staatslehre.

23. Rechtssatz lo traducimos, siguiendo la tradición, como "proposición jurídica". Equivale a la norma legal completa, comprensiva del supuesto de hecho y de la consecuencia jurídica o sanción.

Facultad de Derecho y Ciencias Sociales - Universidad de Valparaíso - Chile 
Georg Jellinek. Yo he tenido la suerte de poder contarme entre sus discípulos. Lo que él significa para la ciencia lo sabe todo aquel que se relacione con la moderna Teoría del Derecho del Estado. Casi todas las páginas de este libro [Hauptprobleme] son muestra del poderoso influjo que él ha ejercido en el desarrollo de la Teoría del Estado. Incluso allí donde he llegado a conclusiones distintas de las que él mantuvo lo he hecho en gran medida por caminos por él abiertos, por caminos que él anduvo antes, como maestro inalcanzable. Ojalá que a mi trabajo le sea dado el contribuir a la memoria de este gran hombre" ${ }^{24}$.

El Prólogo del trabajo de habilitación está fechado en Viena, febrero de 1911. El último párrafo, inmediatamente después del trascrito en referencia a Jellinek, va destinado a agradecer a diversos profesores de la Universidad de Viena: Edmund Bernatzik ("mi venerado maestro"), Adolf Menzel y Friedrich Tezner ("cuyo decidido apoyo y cálida simpatía me han consolado de muchas cosas que se han interpuesto en el desarrollo de mi trabajo”). También menciona a Gerhard Anschütz (“de Berlín, por haberme permitido participar en sus seminarios" $)^{25}$.

Esta obra es muy importante para comprender bien el nacimiento de la Teoría pura del Derecho, que Kelsen desarrollaría a lo largo de su dilatada vida. Tiene un carácter fundamentalmente polémico, pues en ella se pasa revista crítica a las principales contribuciones de la Teoría del Derecho y del Estado. El centro de su interés lo constituyen las cuestiones metodológicas. Kelsen se enfrenta en ella sobre todo a las tendencias que, dentro del positivismo, se sitúan en la línea del psicologismo y del sociologismo. Aunque concebida en las coordenadas intelectuales del positivismo legalista ${ }^{26}$, se deja ver en ella el influjo poderoso del neokantismo y también en ocasiones, aunque menos

\footnotetext{
24. Hans Kelsen, Hauptprobleme, primera edición, citada, p. XIII.

25. Hans Kelsen, Hauptprobleme, primera edición, citada, p. XIII.

26. En vano buscará el lector en esta obra de Kelsen la concepción jerárquica del orden jurídico (Stufenbautheorie) o el consiguiente tratamiento de la validez jurídica y de la norma fundamental. La concepción del Derecho de Hauptprobleme es una concepción plana, para la cual el Derecho es, sencillamente, la ley.
}

Revista de Ciencias Sociales - Número 62 (2013) - Universidad de Valparáíso - ISSN 0716-7725-Valparaíso, Chile 
pronunciado, de la fenomenología. Como su título indica, la revisión de los problemas fundamentales de la Teoría del Derecho del Estado se lleva a cabo a partir de una determinada concepción de la norma de Derecho o proposición jurídica. Concibe Kelsen la norma jurídica como un juicio hipotético que conecta un supuesto de hecho y una consecuencia jurídica por medio de un nexo de deber o deber-ser. Parte, por consiguiente de una concepción homogénea de las normas de Derecho. A partir de la estructura de la Rechtssatz se propone dar respuesta a los conceptos jurídicos básicos.

La estructura de la obra es muy sencilla, por mucho que su desarrollo sea prolijo y complejo para el lector. La divide en tres "libros". El primero lleva por título "Investigaciones preliminares", y en él se abordan las cuestiones básicas del método jurídico. En esta parte es donde más se percibe la influencia neokantiana. Tras estudiar la diferencia entre las leyes de las ciencias naturales y las normas, pasa en un segundo capítulo al análisis de la distinción entre la ley moral y la norma jurídica, y concluye con el examen de la relación entre el punto de vista causal-teleológico y el punto de vista normativo. En el libro segundo se centra en la forma objetiva en que se presentan las proposiciones o normas jurídicas, o sea, en qué sea el Derecho entendido como realidad objetiva. Tras criticar el concepto ingenuo del psicologismo jurídico — que penetra todas las construcciones de la época bajo el signo del imperativismo o tesis de la voluntad-, pasa al estudio de la forma lógica de la proposición jurídica, tanto en sentido estricto - en cuanto que la norma va dirigida a los súbditos — como en sentido amplio - en tanto que obliga al Estado. El libro tercero es con mucho el más extenso. Se limita a extraer las conclusiones de los dos anteriores y a criticar las posiciones contrarias. Su objeto es la investigación de las formas subjetivas en que aparecen las normas del Derecho. Por una parte, y con carácter prioritario, el deber jurídico. y, por otra, y como consecuencia derivada de los deberes jurídicos, la teorización del derecho subjetivo.

Kelsen se plantea en esta obra la lucha contra el "sincretismo" o mezcla de métodos que caracteriza a la Jurisprudencia tradicionalmente, la cual, para verse constituida en una ciencia autónoma, tiene que prescindir de los enfoques extrajurídicos. Con esta expresión se refiere

Facultad de Derecho y Ciencias Sociales - Universidad de Valparaíso - Chile 
sobre todo a la Sociología y a la Psicología. Los presupuestos filosóficos de los que parte se pueden resumir en estos dos: separación de ser (sein) y deber ser (sollen), y separación de forma y contenido.

La primera distinción le lleva a diferenciar las ciencias explicativas y las ciencias normativas. Las primeras tienen por objeto la investigación del ser, esto es, de la facticidad, por medio de la explicación causalista, llegando así a obtener - como resultado de sus investigaciones- leyes de naturaleza de carácter causal. Las segundas, por el contrario, tienen por objeto de estudio el deber ser en cualquiera de sus manifestaciones, lo que significa que manejan el principio de imputación como el característico de las normas. La Jurisprudencia no es una ciencia causalista, sino normativa.

La separación de forma y contenido le lleva a la defensa de la pureza del método, aunque en esta obra aún no aparece la expresión reine Rechtslehre (Teoría pura del Derecho) ${ }^{27}$. Se trata obviamente de conseguir la "pureza" (Reinheit) del método, y no — como a veces se ha interpretado- la pureza del Derecho. Kelsen sostiene que la Jurisprudencia es una ciencia formal, cuyo objeto viene a ser desarrollar una a modo de "geometría del fenómeno jurídico total" 28 .

Es en base a estas ideas como Kelsen propone en esta obra construir la Teoría general del Estado. Para ello, defiende la necesidad de renunciar a la dualidad Derecho público / Derecho privado, pues todo el Derecho es Derecho estatal. La Teoría general del Derecho ha de ser una disciplina unitaria que elabore los conceptos jurídicos de tal modo que reflejen al conjunto del Derecho y no tan sólo a una parte. De ahí que en sus análisis Kelsen no se limite al ámbito del "Derecho del Estado" — esto es, al Derecho constitucional y administrativosino que amplía su trabajo teórico al Derecho privado y al Derecho penal. Ésta me parece una gran idea, que comparto plenamente. La

27. Expresión que, sin embargo, sí aparece en Kant y en Stammler. El primero en su Metaphysik der Sitten, p. 503. El segundo en su Theorie der Rechtswissenschaft.

28. El influjo de Hermann Cohen es evidente, aunque Kelsen no lo cita. Seguramente porque no conocía aún su obra. El neokantismo debía estar en el ambiente intelectual y académico, tanto de Viena como, sobre todo, de Heidelberg.

Revista de Ciencias Sociales - Número 62 (2013) - Universidad de Valparaíso - ISSN 0716-7725-Valparaíso, Chile 
Teoría del Derecho no puede guiarse por los conceptos y modos de pensar más característicos de una rama del ordenamiento, sino que ha de ser capaz de considerar el Derecho en su integridad y en su complejidad. Esta labor de construcción conceptual ha de limitarse, según Kelsen, a un único nivel, que ha de guiarse por la mayor economía posible en la formación de los conceptos.

La recepción de Hauptprobleme fue más bien escasa y fría. En un principio tan sólo fue objeto de un breve comentario en una recensión — publicada en los Kant-Studien — sobre las obras de filosofía de reciente aparición ${ }^{29}$. Friedrich Tezner publicó un trabajo sobre la concepción de proposición o norma jurídica (Rechtssatz) que Kelsen defiende en la $\mathrm{obra}^{30}$; y poco después, Franz Weyr publicó un trabajo titulado "En torno a dos aspectos capitales de la Teoría del Derecho y del Estado de Kelsen"31.

Ese mismo año (1911) publicó Kelsen un opúsculo sobre las fronteras entre el método jurídico y el método sociológico ${ }^{32}$, en el cual profundiza en las diferencias entre la ciencia del Derecho y la sociología jurídica, siguiendo ideas ya expuestas en Hauptprobleme. En julio de 1911 se hace cargo de la docencia de Teoría de la Constitución y de la Administración en la "Exportakademie des k.k. österreichischen

29. Oscar Ewald, "Die deutsche Philosophie im Jahre 1911", en: Kant-Studien 17 (1912), pp. 382-433. Este autor llama la atención sobre el influjo del neokantismo en la obra de Kelsen. Parece ser que, a raíz de este comentario, Kelsen se interesó por conocer el neokantismo.

30. Freidrich Tezner, "Betrachtungen über Kelsens Lehre vom Rechtssatz", en: Archiv des öffentlichen Rechts, volumen 28, 1912, pp. 325-344. Recogido posteriormente en: 33 Beiträge zur Reinen Rechtslehre, herausgegeben von Rudolf Alad ár Métall, Europaverlag, Wien 1974, pp. 437-454.

31. Franz Weyr, "Über zwei Hauptpunkte der Kelsenschen Staatsrechtslehre", en: Grünhuts Zeitschrift für das Privat-und öffentliche Recht der Gegenwart, volumen 40, 1913, pp. 175-188. Recogido posteriormente en: 33 Beitráge zur Reinen Rechtslehre, herausgegeben con Rudolf Aladár Métall. Europaverlag, Wien 1974, pp. 455-466.

32. Hans Kelsen, Grenzen juristischer und soziologischer Methode, J.C.B. Mohr (Paul Siebeck), Tübingen 1911.

Facultad de Derecho y Ciencias Sociales - Universidad de Valparaíso - Chile 
Handelsmuseum"33 en Viena. Y en el otoño comienza su actividad docente de las materias para las que fue habilitado (Derecho del Estado o Derecho político y Filosofía del Derecho).

En 1912 contrae matrimonio con Margarete Bondi. Del matrimonio nacerían dos hijas: Anna Renate (1914-2001) y Maria Beate (1915-1994).

Durante esos años antes de la guerra Kelsen publicó recensiones y algunos trabajos en los cuales va concretando ciertos aspectos de lo que más tarde será la teoría pura del derecho ${ }^{34}$.

\section{Los años de la guerra}

En 1914 comienza la Primera Guerra Mundial. La vida de Kelsen va a experimentar un cambio notable que, a la postre — como vamos a ver- le favoreció mucho en su carrera académica. Es llamado a filas en agosto y pronto cae enfermo, al parecer con una pulmonía. Ya curado, y dada su condición de jurista, se le destina a trabajos de oficina. Al cabo de un tiempo, un buen día recibe la orden de presentarse ante el general Stöger-Steiner. Kelsen se quedó sorprendido y preocupado por esa orden, pues no tenía idea cuál podría ser el motivo. Cuando acudió al despacho del general se lo encontró hecho una furia. Reprochó a Kelsen que hubiera publicado un artículo de Derecho militar sin permiso suyo. Para sorpresa del general, Kelsen le replicó que él no había publicado

33. Esta institución a partir de 1919 recibirá el nombre de "Hochschule für Welthandel”, y desde 1975 el de "Wirtschaftsuniversität Wien”.

34. Especialmente los siguientes: Hans Kelsen: "Zur Soziologie des Rechts. Kritische Betrachtungen”, en: Archiv für Sozialwissenschaft und Sozialpolitik, vol. 34, 1912, pp. 601-614. "Politische Weltanschauung und Erziehung", en: Annalen für soziale Politik und Gesetzgebung, vol. 2, 1913; pp. 1-26. "Rechtsstaat und Staatsrecht", Österreichische Rundschau, Vol. 36, 1913, pp. 88-94. "Über Staatsunrecht. Zugleich ein Beitrag zur Frage der Deliksfähigkeit juristischer Personen und zur Lehre vom fehlerhaften Staatsakt. Grünhuts Zeitschrift für das Privat- und öffentliche Recht der Gegenwart, vol. 40, 1913, pp. 1-114. "Zur Lehre vom Gesetz im formellen und materiellen Sinn, mit besonderer Berücksichtigung der österreichischen Verfassung”, Juristische Blätter, 42. Jahrgang, 1913, pp. 229-232. "Zur Lehre vom öffentlichen Rechtsgeschäft”, en: Archiv des öffentlichen Rechts, vol. 31, 1913, pp. 53-98, 190-249.

Revista de Ciencias Sociales - Número 62 (2013) - Universidad de Valparáiso - ISSN 0716-7725-Valparáís, Chile 
ningún artículo de Derecho militar. Stöger-Steiner le enseñó entonces la revista en que efectivamente aparecía el artículo firmado por Hans Kelsen. Éste reconoció al instante que el trabajo era suyo y que se había olvidado del asunto al dárselo a un oficial que quería fundar una revista de derecho militar. Se dio cuenta en la conversación con el general de por medio había una cuestión de competencias, y le explicó entonces que él no tenía ni idea de tal potencial conflicto y que lo único que quería era servir a sus superiores —o sea, al propio general- con absoluta lealtad. Aclarado el incidente la conversación fue trascurriendo por otros derroteros, y cuando ya estaban a punto de despedirse el general le dijo: “¿Quiere usted ser mi asesor jurídico?” Kelsen aceptó inmediatamente. Este hecho cambió la vida de Kelsen. No sólo le permitió seguir sus estudios sino que le posibilitó asimismo ir conociendo a buen número de personalidades militares y políticas durante el tiempo que duró la guerra. Esta situación se vio favorecida sobremanera cuando el general Stöger-Steiner fue nombrado Ministro de la Guerra.

Durante esos años Kelsen siguió con su actividad de publicista. Destacan algunos de sus trabajos que comento a continuación.

Buena prueba de su carácter y de su espíritu crítico nos la da la polémica que sostuvo con Eugen Ehrlich (1862-1922), a la sazón Rector de la Universidad de Cernowitz, ciudad ésta que entonces pertenecía al Imperio Austro-Húngaro y hoy forma parte de Ucrania. Ehrlich era un conocido romanista que había publicado varios trabajos sobre jurisprudencia sociológica y que había abierto el camino del llamado "movimiento del derecho libre" (Freirechtsbewegung). En 1913 publica lo que bien puede considerarse el primer tratado de sociología jurídica propiamente dicha, titulado Grundlegung der Soziologie des Rechts (Fundamentación de la Sociología del Derecho) ${ }^{35}$. Uno de los propósitos de Ehrlich era criticar la jurisprudencia tradicional de los juristas para negarle el carácter de verdadera ciencia, y así proponer su sustitución por la auténtica ciencia del derecho que, a su juicio, no podía ser otra que la Sociología jurídica. Aunque en esta obra no se cita a Kelsen, éste

35. Eugen Ehrlich, Grundlegung der Soziologie des Rechts, Duncker \& Humblot, Berlin 1913.

Facultad de Derecho y Ciencias Sociales - Universidad de Valparaíso - Chile 
se sintió sin duda aludido, no porque pensara que Ehrlich lo hubiese leído, sino por la sencilla razón de que el Rector de Cernowitz defendía justo las tesis contrarias a las que él había expuesto en sus Hauptprobleme y en los trabajos posteriores.

Kelsen puso manos a la obra y publicó una extensa recensión del libro de Ehrlich, que apareció en $1915^{36}$. El tono de esta recensión es muy duro, incluso puede decirse que desconsiderado. Kelsen emplea adjetivos tales como "absurdas" y "grotescas" para referirse a las ideas defendidas por Ehrlich. Éste le contestó en un breve escrito, al cual Kelsen replicó. Nueva respuesta de Ehrlich, y conclusión final de Kelsen. La polémica, exabruptos aparte, constituye un interesante debate en el cual quedan expuestos dos puntos de vista. No me cabe duda de que el desarrollado por Kelsen ostenta una mayor reciedumbre que el defendido por Ehrlich; pero eso se debe en gran parte a que, como éste último dice, la Sociología del Derecho era entonces una ciencia que daba sus primeros pasos ${ }^{37}$. Según he leído en algún lugar — que no he podido concretar- Kelsen, estando ya en Berkeley, comentó que había estado desacertado en la mencionada polémica y que ello había contribuido en parte a que la Sociología del Derecho no se asentara en Austria como una disciplina autónoma. Es posible que hiciera esta observación al haber comprobado que en EEUU la Sociología jurídica gozaba de mejor salud que en Europa.

\footnotetext{
36. Hans Kelsen, "Eine Grundlegung der Rechtssoziologie", en: Archiv für Sozialwissenschaft und Sozialpolitik, vol. 39, 1915, pp. 839-876.
}

37. Gregorio Robles: "Normativismo versus sociologismo: comentario de una polémica”, en: Anuario de Filosofía del Derecho, Instituto Nacional de Estudios Jurídicos, Madrid 1975-1976; recogido después con el título "Normativismo y sociologismo: la polémica entre Kelsen y Ehrlich en torno a la naturaleza de la ciencia jurídica” en G. Robles, Epistemología y Derecho, Pirámide, Madrid, 1982, pp. 27-41. Véase también G. Robles, Ley y derecho vivo. Método jurídico y sociología del derecho, Centro de Estudios Políticos y Constitucionales, Madrid 2002, especialmente capítulos XII ("Normativismo legalista y sociologismo: la polémica entre Kelsen y Ehrlich”) y XIII ("Conclusión: la aportación de Ehrlich a la sociología jurídica y al movimiento del derecho libre").

Revista de Ciencias Sociales - Número 62 (2013) - Universidad de Valparáíso - ISSN 0716-7725-Valparaíso, Chile 


\section{La Escuela de Viena}

Las circunstancias que rodearon a Kelsen durante la guerra favorecieron su entrada definitiva en la Universidad de Viena. El propio Bernatzik le insinuó que su situación había cambiado radicalmente debido a las relaciones que Kelsen había establecido en aquellos años. En octubre de 1918 es nombrado profesor extraordinario (ausserordentlicher Profesor), y al mes siguiente comienza su colaboración para elaborar, por encargo del Canciller Karl Renner, la nueva Constitución de la República de Austria. Tras el fallecimiento de Edmund Bernatzik, es nombrado miembro del Tribunal Constitucional en marzo de 1919. Asimismo accede a la cátedra sucediendo a Bernatzik: es nombrado Ordentlicher Universitätsprofessor de Derecho del Estado y Derecho Administrativo en la Universidad de Viena. Eso sucedía el 1 de agosto de 1919. Puede afirmarse que, con este nombramiento, Kelsen había logrado hacer realidad su propósito de ser catedrático. Comenzaba así una época de gran intensidad, como profesor y como magistrado del Tribunal Constitucional.

En torno a Kelsen se había ido formando un grupo de jóvenes juristas que pronto se conocería en el mundo del Derecho como la Escuela de Viena. Kelsen había organizado un seminario privado que se reunía normalmente los domingos por la tarde en el domicilio de Kelsen, que estaba en la Wickenburggasse número 23, a un paseo de diez minutos de la Universidad. En esas reuniones se discutieron las ideas de los componentes del seminario, entre los cuales destacan, como juristas renombrados y que acabarían teniendo una gran obra, Adolf Julius Merkl y Alfred Verdross. Menos conocidos, pero también relevantes por su producción científica, fueron, entre otros, Fritz Sander, Leonidas Pitamic, Fritz Schreier y Felix Kaufmann. Un rasgo de este último es que, dada su formación en materias muy dispares — desde el Derecho a las Matemáticas pasando por las Ciencias sociales y la Economía, compatibilizó su participación en varios círculos científicos ${ }^{38}$.

38. Además del seminario privado de Kelsen, Kaufmann fue asiduo del Wiener Kreis (positivismo lógico) dirigido por Moritz Schlick, del seminario del economista Ludwig von Mises y del llamado Geist-Kreis.

Facultad de Derecho y Ciencias Sociales - Universidad de Valparaíso - Chile 
Lo que caracterizaba al grupo no era que todos siguieran una misma línea ideológica o científica, sino la puesta en común de sus inquietudes teóricas. Kelsen fue un maestro liberal que, si bien defendió sus posiciones con rigor y a veces con verdadera pasión, nunca quiso que prevalecieran por el mero hecho de su auctoritas.

La década de los años 20 fue para la Escuela y para el propio Kelsen una etapa prodigiosa que se manifiesta en su impresionante producción científica.

En 1920 publica su monografía sobre el problema de la soberanía y la teoría del Derecho internacional, en la cual aparece por primera vez en el título la expresión "Teoría pura del Derecho"39, y en el mismo año ve la luz un importante estudio sobre socialismo y Estado ${ }^{40}$.

En 1922 publica otra monografía en la que defiende la identidad entre Derecho y Estado, y critica acerbamente la posibilidad de un concepto sociológico del Estado ${ }^{41}$.

Tres años después, en 1925, recoge todas sus investigaciones sobre el Estado en su monumental obra Allgemeine Staatslehre ${ }^{42}$. Esta obra es traducida por Luis Legaz Lacambra y aparece publicada en España en $1934^{43}$.

En el "Prólogo" Kelsen nos proporciona las claves para entender su pensamiento sobre el Estado - $\mathrm{O}$, al menos, las claves de tal como entiende él su propia obra—. Se propone — nos dice— una Teoría del

39. Hans Kelsen, Das Problem der Souveränität und die Theorie des Völkerrechts. Beitrag zu einer reinen Rechtslehre, J.C.B. Mohr (Paul Siebeck), Tübingen 1920; reimpresión 1928.

40. Hans Kelsen, Sozialismus und Staat. Eine Untersuchung der politischen Theorie des Marxismos, C.L. Hirschfeld, Leipzig 1920.

41. Hans Kelsen, Der soziologische und der juristische Staatsbegriff. Kritische Untersuchung des Verhältnisses von Staat und Recht, J.C.B. Mohr (Paul Siebeck), Tübingen 1922.

42. Hans Kelsen, Allgemeine Staatslehre, Julius Springer, Berlin 1925.

43. Hans Kelsen, Teoría general del Estado, traducción por Luis Legaz Lacambra, Labor, Barcelona-Madrid-Buenos Aires, 1934.

Revista de Ciencias Sociales - Número 62 (2013) - Universidad de Valparáíso - ISSN 0716-7725-Valparaíso, Chile 
Estado "desde el punto de vista de la pureza metódica", lo cual le lleva ineludiblemente a la confrontación con la "doctrina dominante”. Y declara: "Ahora, al resumir y completar los resultados de mis anteriores trabajos monográficos en un sistema de Teoría general del Estado, veo con más claridad que antes hasta qué punto descansa mi labor en la de los grandes predecesores: ahora me siento más unido que nunca a aquella dirección científica que tuvo en Alemania como sus representantes más ilustres a Karl Friedrich von Gerber, Paul Laband y Georg Jellinek. Esta dirección, apartándose de la nebulosa metafísica del Estado, pretendía ser una Teoría del Estado positivo, esto es, una Teoría del Estado estrictamente jurídica, sin matiz político alguno. Esa teoría era una parte del gran movimiento científico-social que — paralelamente a una evolución análoga en el dominio de las ciencias naturales - se dirigía contra la especulación jusnaturalista del siglo XVIII, y aspiraba, apoyada en la escuela histórica del primer tercio del siglo XIX, a constituir una teoría de la sociedad real (Sociología) y del Derecho positivo. Su método estaba influido, más o menos consciente y consecuentemente, por la crítica kantiana de la razón: dualismo de ser y deber ser; sustitución de hipóstasis y postulados metafísicos por categorías trascendentales como condiciones de la experiencia; transformación de antítesis absolutas (por cualitativas y transistemáticas) en diferencias relativas, cuantitativas, intrasistemáticas; paso de la esfera subjetivista del psicologismo al ámbito de la validez lógico-objetiva: he aquí algunos momentos esenciales de este método, y las directrices de mi labor teórica" ${ }^{44}$.

La obra se divide en tres libros. El primer libro trata de "la esencia del Estado”. En él, tras criticar la Teoría del Estado entendida como Sociología y como Política, defiende la idea fundamental, a saber: La Teoría del Estado es Teoría del Derecho del Estado, y, en definitiva, la idea de que el Estado es el Derecho. El libro segundo trata de la Estática, esto es, de la validez del orden estatal, que es lo mismo que la validez del orden jurídico. Dentro de este libro estudia la estructura espacial del Estado — como espacio de la validez jurídica- y sus diversas

44. Hans Kelsen, Teoría general del Estado, traducción de Luis Legaz Lacambra, citado, pp. VII-VIII.

Facultad de Derecho y Ciencias Sociales - Universidad de Valparaíso - Chile 
manifestaciones organizativas. Por último, el libro tercero se centra en la exposición de la Dinámica, o sea, en la creación del orden estatal, que equivale a la creación del orden jurídico. Tras analizar la teoría de los poderes o funciones del Estado, pasa a la teoría de los órganos y concluye con los métodos de creación del Derecho — que equivale al estudio de las formas del Estado.

La Teoría general del Estado fue resumida en 1926 en un breve volumen ${ }^{45}$ que se publicó en español traducido por Luis Recaséns Siches y Justino de Azcárate ${ }^{46}$. Se tradujo asimismo al francés, al italiano, al griego, al chino, al japonés, al portugués, al rumano, al checo y al húngaro; lo que sin duda contribuyó a la expansión de las ideas jurídicas del creador de la teoría pura del derecho.

Entre los trabajos publicados por Kelsen en los años siguientes sobresalen su estudio sobre los fundamentos filosóficos de la teoría del derecho natural y del positivismo jurídico ${ }^{47}$ y, sobre todo, Valor y Esencia de la Democracia ${ }^{48}$.

Durante esta década de los años 20, los componentes de la Escuela de Viena publicaron libros muy importantes.

Los trabajos de Adolf J. Merkl (Viena 1890 - Viena 1970) tuvieron una notable influencia en el desarrollo de la Teoría pura del Derecho. El propio Kelsen calificó a Merkl de "genio del pensamiento jurídico" y asimismo de "cofundador de la Teoría pura del Derecho". Así se le

45. Hans Kelsen, Grundriss einer allgemeinen Theorie des Staates. Als Manuskript gedruckt. Wien 1926.

46. Hans Kelsen, Compendio esquemático de una Teoría general del Estado, traducido por Luis Recaséns Siches y Justino de Azcárate Flórez, con Introducción de Luis Recaséns Siches. Núñez y Comp., Barcelona 1928. Segunda edición ampliada, Bosch, Barcelona, 1934.

47. Hans Kelsen, Die Philosophischen Grundlagen der Naturrechtslehre und des Rechtspositivismus, Pan-Verlag Rolf Heise, Charlottenburg 1928.

48. Hans Kelsen, Vom Wesen und Wert der Demokratie, segunda edición ampliada, J.C.B. Mohr (Paul Siebeck), Tübingen 1929. Traducción al español de Rafael Luengo Tapia y Luis Legaz Lacambra, Labor, Barcelona-Buenos Aires, 1934. La primera edición en alemán es del año 1920 y es mucho más breve.

Revista de Ciencias Sociales - Número 62 (2013) - Universidad de Valparáiso - ISSN 0716-7725-Valparáís, Chile 
puede considerar, en efecto, dada su aportación decisiva en el ámbito de la teoría de la "dinámica jurídica” y dentro de ella, más en concreto, de la estructura jerárquica del ordenamiento jurídico, que elaboró en profundidad siguiendo los pasos de Bierling.

Los profesores que más impresionaron a Merkl en su paso por la Facultad fueron Edmund Bernatzik, Hans Kelsen y Adolf Menzel. En 1915 comienza a asistir a las sesiones del seminario privado de Kelsen, con el cual trabajaría en la elaboración del proyecto de Constitución austriaca de 1920. Además de sus trabajos sobre dicha Constitución ${ }^{49}$, sobresale por encima de todos su tratado de Derecho administrativo ${ }^{50}$. Singular relieve adquirieron sus trabajos de Teoría del Derecho, entre los cuales sobresalen las monografías dedicadas a la doctrina de la "fuerza jurídica" ${ }^{51}$ y a la teoría de la estructura escalonada del ordenamiento jurídico ${ }^{52}$.

Alfred von Verdross (Innsbruck 1890 —-Innsbruck 1980) pronto centró sus intereses académicos en el Derecho internacional público, pero no por eso dejó de elaborar ideas para la Teoría pura del Derecho. En especial ideó el concepto de "constitución en sentido lógicojurídico" ${ }^{3}$ dando así una definición apropiada a la idea de la norma fundamental (Grundnorm). Contribuyó además a uno de los dogmas básicos de la Escuela de Viena: el principio del monismo del mundo jurídico, sobre todo en sus obras sobre la unidad de la imagen jurídica

49. Adolf J. Merkl, Die Verfassung der Republik Deutsch-Österreich. Ein kritischsystematischer Grundriss, Wien \& Leipzig, 1919.

50. Adolf J. Merkl, Allgemeines Verwaltungsrecht, Wien \& Berlin, 1927. Hay traducción española en Editorial Revista de Derecho Privado, Madrid 1932.

51. Adolf J. Merkl, Die Lehre von der Rechtskraft, entwickelt aus dem Rechtsbegriff. Eine rechtstheoretische Untersuchung, Wien \& Leipzig, 1923.

52. Adolf J. Merkl, "Prolegomena einer Theorie des rechtlichen Stufenbaues", en: Gesellschaft, staat und Recht. Festschrift gewidmet Hans Kelsen zum 50. Geburtstag, Wien 1931, pp. 252-294.

53. Alfred von Verdross, "Zum Problem der Rechtsunterworfenheit des Gesetzgebers”, en: Juristische Blätter, 45. Jahrgang, 1916, pp. 471 y ss.

Facultad de Derecho y Ciencias Sociales - Universidad de Valparaíso - Chile 
del mundo sobre la base de la constitución del derecho internacional ${ }^{54}$, y sobre la constitución de la comunidad jurídica internacional ${ }^{55}$. Su tratado de derecho internacional se ha convertido en un clásico de esa disciplina. Publicado por primera vez en $1937^{56}$, alcanzó varias ediciones; también posteriormente, en colaboración con Bruno Simma ${ }^{57}$. El profesor Antonio Truyol Serra tradujo al español esta obra ${ }^{58}$.

Otro importante componente de la Escuela de Viena fue Fritz Sander (1889-1939). Al parecer fue en un principio el discípulo preferido de Kelsen, pero un incidente desagradable enfrió sus relaciones. Sander acusó a Kelsen de plagio. Éste entonces, para investigar el asunto, solicitó de las autoridades académicas la apertura de un expediente contra sí mismo. Por supuesto, Kelsen fue hallado inocente de semejante acusación. Al respecto puede leerse en la "Autobiografía" (1947); "Entre mis discípulos, de los que se habilitaron en esos años, se encontraba también Fritz Sander. Cuando en torno a 1915 comenzó a participar en mi seminario me dijo que no tenía intención de dedicarse a la carrera académica, sino que quería ser abogado. Estimulado por los debates en el seminario, comenzó a trabajar en temas de Teoría del Derecho, y así fue como le publiqué su primer trabajo en la Zeitschrift des öffentlichen Rechts, que yo dirigía. Se trataba de una contribución muy relevante a la Teoría del Derecho desde la perspectiva de la lógica trascendental kantiana. Sander fue, sin duda alguna, uno de mis discípulos mejor dotados, gran trabajador, con ideas originales y con una energía

\footnotetext{
54. Alfred von Verdross, Die Einheit des rechtlichen Weltbildes auf Grundlage der V ölkerrechtsverfasung, Tübingen 1923.

55. Alfred von Verdross, Die Verfassung der Völkerrechtsgemeinschaft, Wien 1926.

56. Alfred von Verdross, Völkerrecht, Wien 1937; 5ª edición, 1964.

57. Alfred Verdross \& Bruno Simma, Universelles Völkerrecht. Theorie und Praxis, Duncker \& Humblot, Berlin, tercera edición 1984.
}

58. Alfred Verdross, Derecho internacional público. Traducción directa de la $4^{\mathrm{a}}$ edición alemana, refundida y aumentada, en colaboración con Karl Zemanek, con notas y bibliografías adicionales por Antonio Truyol y Serra, Aguilar, Madrid 1963.

Revista de Ciencias Sociales - Número 62 (2013) - Universidad de Valparáíso - ISSN 0716-7725-Valparaíso, Chile 
intelectual extraordinaria. Era completamente natural que muy pronto intentara seguir su propio camino, separándose de la dirección en la que yo venía trabajando. Los demás discípulos hicieron lo mismo en una u otra medida, y yo siempre busqué animarles a todos ellos, y especialmente a Sander, (...), a que se desarrollaran intelectualmente de manera autónoma. Creo que el mayor error que puede cometer un maestro es esperar de sus discípulos un mero jurare ad verba magistri. Hasta qué punto me preocupé de apoyar a Sander, lo demuestra el que no sólo conseguí que se habilitara, en contra de una fuerte oposición, sino también que le publicara - a pesar de los graves inconvenientes que planteaba la editorial — en los Wiener Staatswissenschaften Studien que yo a la sazón dirigía, su obra en dos volúmenes titulada Staat und $R e c h t^{59}$, obra con la cual yo disentía en muchos aspectos. Un día Sander me trajo un manuscrito para su publicación en la Zeitschrift für Öffentliches Recht, en él atacaba con gran dureza y, en mi opinión, de manera no muy fundamentada, algunas posiciones de mi Teoría del Derecho $^{60}$. Le dije que naturalmente publicaría su trabajo, pero que me reservaba el contestarle. Mi respuesta apareció con el título Rechtswissenschaft und Recht. Erledigung eines Versuchs zur Überwindung der Rechtsdogmatik $k^{61}$. Mi rivalidad con Sander en aspectos teóricos no me impidió, sin embargo, apoyarle con decisión para una cátedra en la Universidad alemana de Praga. Sander obtuvo esa plaza y creo que eso sucedió en gran parte gracias a mi apoyo. Apenas se sintió seguro en esa cátedra, se pronunció públicamente contra mí asegurando que yo había tomado de él partes sustanciales de mi teoría sin reconocerlo, como es obligado. Se trataba de un claro reproche de plagio. De

59. Fritz Sander, Staat und Recht. Prolegomena zu einer Theorie der Rechtserfahrung, Leipzig und Wien 1922. La obra es, en efecto, muy extensa: en conjunto, 1.304 páginas.

60. Fritz Sander, "Rechtsdogmatik oder Theorie des Rechtserfahrung? Kritische Studie zur Rechtslehre Hans Kelsens, en: Zeitschrift für öffentliches Recht 2 (1921), pp. 511-670.

61. Hans Kelsen, "Rechtswissenschaft und Recht. Erledigung einer Versuchs zur Überwindung der 'Rechtsdogmatik', en: Zeitschrift für öffentliches Recht 3 (1922/23), pp. 103-235.

Facultad de Derecho y Ciencias Sociales - Universidad de Valparaíso - Chile 
inmediato solicité una investigación disciplinar contra mí mismo, la cual condujo a mi exculpación total”².

El escrito en el que Sander formuló su acusación contra Kelsen indica ya en el subtítulo su intención: "Escrito de lucha (Kampfschrift) contra la jurisprudencia normativa" ${ }^{63}$. Kelsen presentó la solicitud de expediente contra sí mismo el 7 de mayo de 1923, y la respuesta la obtuvo el 16 de julio del mismo año. En ella se declaraba que al profesor Kelsen no se le podía hacer "el más mínimo reproche".

Después de este incidente Kelsen no quiso saber nada de Sander, a pesar de las muestras que éste daba de su deseo de volver a tener buenas relaciones con su maestro. No obstante, pasado algún tiempo y a instancias de Franz Weyr, amigo de Kelsen y profesor en la Facultad de Derecho de Praga, se reanudaron las relaciones después de que Sander presentara un comunicado en el cual declaraba que reconocía no haber sido objeto de plagio. Kelsen, para explicar la extraña relación que mantuvo con Sander, comenta en su "Autobiografía" que este último tenía hacia él un sentimiento de amor-odio muy acentuado, y que su acusación había sido un acto de "matar al padre", característico del complejo de Edipo — pues, añade, al parecer las relaciones de Sander con su propio padre habían sido sumamente complicadas y conflictivas ${ }^{64}$. En este juicio probablemente influiría el conocimiento que Kelsen tenía del psicoanálisis. Por esos años solía participar en los seminarios de Sigmund Freud, que a la sazón tenía algún encargo de docencia en la Universidad de Viena.

He mencionado el nombre de Franz Weyr (1879-1951), al que Kelsen consideraba un representante de la Teoría pura del Derecho. Fundador de la Escuela de Teoría pura del Derecho de Brünn (Brno, República Checa), es autor de trabajos relevantes de dicha disciplina ${ }^{65}$.

62. Hans Kelsen im Selbszeugnis, op. cit. pp. 64-65.

63. Fritz Sander, Kelsens Rechtslehre. Kampfschrift wider die normative Jurisprudenz, Tübingen 1923.

64. Hans Kelsen im Selbstzeugnis, citado, p. 66.

65. Algunos de los cuales están recogidos en: Kubes-Weinberger, Die Brünner rechtstheoretische Schule (Normative Theorie), Manz Verlag, Wien 1980. Se

Revista de Ciencias Sociales - Número 62 (2013) - Universidad de Valparáíso - ISSN 0716-7725-Valparaíso, Chile 
Kelsen no sólo tuvo en Viena discípulos provenientes de Austria. Pronto acudirían a sus seminarios jóvenes docentes de diversas naciones. Entre ellos cabe destacar a Luis Recaséns Siches (1903-1978) y Luis Legaz Lacambra (1906-1980).

Recaséns estuvo un semestre en Viena en el año 1927. Tomó la decisión de ir a estudiar con el maestro vienés a pesar de la oposición de Heller y Stammler, el cual al parecer llegó a decirle: "No me diga usted que tiene la intención de ir a aprender algo útil de un austriaco" 66 .

Por su parte, Legaz, por sugerencia de Recaséns y pensionado por la Junta de Ampliación de Estudios, llegó a Viena a comienzos de 1929. Su idea era trabajar en un estudio sobre la Teoría pura del Derecho, con el objeto de revisar y someter a crítica sus fundamentos filosóficos. El contacto con la Escuela de Viena constituyó para el joven iusfilósofo español una experiencia que dejó en él una huella indeleble ${ }^{67}$. El curso que Legaz estuvo en la Universidad de Viena fue el último en que Kelsen impartió docencia en sus aulas, antes de ir a la Universidad de Colonia. Legaz asistió a sus lecciones de Teoría del Estado, frecuentó

recogen asimismo en este volumen estudios de otros integrantes de la Escuela de Brünn, entre los cuales sobresale Karel Englis. Englis fue ministro de hacienda de Checoslovaquia y Director del Banco Nacional. En español disponemos de su obra Introducción a la ciencia financiera, traducción directa del checo de Milic Kybal, Editorial Labor, Barcelona-Madrid-Buenos Aires-Río de Janeiro 1937. Vladimir Kubes subraya en su trabajo introductorio de la obra citada en primer lugar que Englis, junto a otros, constituyó la Escuela de Economía Política, próxima a la de Teoría del Derecho, en el sentido de asentarse aquella sobre "una teoría formal de la teleología (esto es, de los sistemas teleológicos, de las relaciones medios-fines y de las decisiones electivas determinadas por aquellos sistemas" (Die Brünner rechtstheoretische Schule, p. 16).

66. Benito de Castro, “Luis Recaséns Siches”, en: Rafael Domingo (ed.), Juristas universales. 4. Juristas del siglo XX, Marcial Pons, Madrid-Barcelona, 2004, pp. 427-430, p. 428.

67. Gregorio Robles, “Luis Legaz y Lacambra (1906-1980): Un permanente diálogo con Hans Kelsen”, en Gregorio Robles Morchón \& Diego Medina Morales (coordinadores), Ensayos sobre el Derecho y la Justicia. Libro Homenaje a Ana Cebeira Moro, Colección Seminario de Filosofía del Derecho no 4, año 2008, Córdoba 2009, pp. 247-287.

Facultad de Derecho y Ciencias Sociales - Universidad de Valparaíso - Chile 
sus seminarios y fue asimismo oyente de cursos monográficos impartidos por Alfred Verdross, Fritz Schreier y Félix Kaufmann. Allí, en fin, preparó su tesis doctoral, que presentó en Madrid en $1932^{68}$.

Provenientes de otros países, estudiaron también en esos años bajo la dirección de Kelsen el danés Alf Ross, el alemán Julius Kraft, el francés Charles Eisenmann, el holandés Marinus Maurits van Praag, el japonés Tomoo Otaka y el polaco Wiktor Sukiennicki ${ }^{69}$.

\section{Participación en el Proyecto de Constitución y en el Tribunal Constitucional}

Al acabar la Guerra, el Canciller Karl Renner (1870-1950) encargó a un equipo de juristas la preparación de un proyecto de Constitución. Uno de los componentes de dicho equipo fue Kelsen. Éste subraya que sólo en cuanto actividad secundaria participó en la tarea, pues su trabajo principal siguió siendo su actividad como catedrático de la Universidad. Renner le dio las directrices básicas y Kelsen se centró, sobre todo, en el capítulo dedicado a las garantías de la Constitución y de la Administración. Para ello — dice- disponía de dos instituciones provenientes de la vieja Monarquía: el Tribunal de Reich (Reichsgericht) y el Tribunal Administrativo (Verwaltungsgerichtshof). "Este último, con ciertas modificaciones no sustanciales, pudo ser incorporado. El Tribunal del Reich fue transformado en un verdadero Tribunal Constitucional —el primero de esta especie en la historia del Derecho constitucional. Hasta entonces ningún tribunal había sido competente para declarar la invalidez, con efectos generales y no limitados al caso en cuestión, de las leyes a causa de su inconstitucionalidad"70.

68. La tesis de Legaz se publicó como libro: Luis Legaz y Lacambra, Kelsen. Estudio crítico de la Teoría pura del Derecho y del Estado de la Escuela de Viena, Bosch, Barcelona 1933, con Prólogo de Luis Recaséns Siches, en el cual éste declara: "Yo le sugerí [a Legaz], hace algunos años, este estudio que ha llevado a cabo por cierto con gran provecho y brillantez" (p. 11).

69. Walter / Jabloner / Zeleny (Hrs.), Der Kreis um Hans Kelsen. Die Anfangsjahre der Reinen Rechtslehre, Manz, Wien 2008.

70. Hans Kelsen im Selbszeugnis, cit., p. 69.

Revista de Ciencias Sociales - Número 62 (2013) - Universidad de Valparáíso - ISSN 0716-7725-Valparaíso, Chile 
A comienzos de mayo de 1919 Kelsen entró a formar parte del Tribunal Constitucional Austriaco, en sustitución de Edmund Bernatzik, que había fallecido a finales de marzo del mismo año. Ejerció como magistrado hasta 1929. Ya para esa época el Tribunal había sufrido algunas críticas partidistas que se fueron enconando progresivamente y que desembocó en el asunto de las dispensas matrimoniales. La cuestión que se debatió entonces fue de carácter procesal, relativa a una cuestión de competencias, en concreto si las dispensas, concedidas por la administración para obtener el divorcio, podían ser impugnadas, y en su caso anuladas, por la vía jurisdiccional ordinaria. Sucedía que muchas dispensas que se habían concedido legalmente por la administración eran anuladas por los jueces, con lo cual se daban situaciones de bigamia. Kelsen, con otros magistrados, se posicionó ante este problema aplicando un criterio que el Tribunal Constitucional había aplicado precedentemente en un asunto distinto, y que se resumía en que la impugnación de los actos administrativos no podía hacerse ante un juez de la jurisdicción ordinaria sino ante la jurisdicción contencioso-administrativa. A todo esto, la polémica fue creciendo en la prensa y en la calle hasta el punto de proferir insultos y amenazas en pintadas frente al domicilio de Kelsen. Todo esto se veía reforzado además por la intención política de cambiar la configuración y el modo de elección de los magistrados del Tribunal Constitucional Austriaco, como efectivamente así sucedió.

Profundamente disgustado y decepcionado por la deriva de los acontecimientos, y aprovechando la invitación que la Universidad de Colonia le había cursado para que formara parte de su claustro, Kelsen decidió abandonar Austria y empezar una nueva etapa de su vida. Unos meses antes había publicado un librito que llegaría a tener un gran éxito, Esencia y Valor de la Democracia ${ }^{71}$, cuya traducción al español por Rafael Luengo Tapia y Luis Legaz y Lacambra apareció pocos años después ${ }^{72}$.

71. Hans Kelsen, Vom Wesen und Wert der Demokratie, zweite, umgearbeitete Auflage, J.C.B. Mohr (Paul Siebeck), 1929.

72. Hans Kelsen, Esencia y valor de la democracia, traducción de la $2^{\text {a }}$ edición alemana por Rafael Luengo Tapia y Luis Legaz y Lacambra, Introducción de Luis Legaz y Lacambra, Labor, Barcelona - Buenos Aires, 1934.

Facultad de Derecho y Ciencias Sociales - Universidad de Valparaíso - Chile 


\section{Colonia}

En la "Autobiografía" declara Kelsen que los tres años que él y su familia vivieron en Colonia fueron extraordinariamente acogedores. Le habían llamado para que explicara la cátedra de Derecho internacional público, disciplina con la que Kelsen sólo había tenido un contacto colateral, derivado de su dedicación a la Teoría general del Estado. En esta materia había abordado sobre todo el problema de las relaciones entre el Derecho internacional y el Derecho estatal, pero carecía de los conocimientos para explicar el Derecho internacional positivo. Por eso, declara que se pasó los tres años que estuvo en la ciudad alemana estudiando este último. Lo que aún no sabía Kelsen es que el resto de su vida sería profesor de Derecho internacional.

Relata Kelsen que las condiciones materiales que él y su familia tuvieron en Colonia fueron muy buenas. Además, recuerda con satisfacción sus excelentes relaciones con los demás profesores de la Facultad, en especial con Fritz Stier-Somlo, que era el catedrático de Derecho político. En 1932 Kelsen fue elegido decano. Todo acabó en abril de 1933. Kelsen se enteró por la prensa de su destitución como catedrático. Narra cómo fue. Aquel día, mientras desayunaba, leía el periódico. Su mujer, que estaba frente a él, le comentó que su nombre aparecía en la página que ella podía leer. La noticia informaba que, en aplicación de la ley de depuración de los funcionarios, el profesor Hans Kelsen quedaba desposeído de su cátedra con efectos inmediatos.

Ante esta situación Kelsen pensó en abandonar Alemania para trasladarse a Ginebra (Suiza), en cuyo Institut Universitaire de Hautes Etudes Internacionales había sido profesor invitado durante el semestre de verano de $1932^{73}$. El problema que se le planteó entonces - teniendo en cuenta que la policía estaba en manos de los nazis - fue el de conseguir un visado que le permitiera atravesar la frontera. Comenta: "Al ser yo pacifista y autor de la Constitución democrática de Austria, era bastante seguro que me deportarían a un campo de concentración, mi situación era francamente desesperanzada. Yo había hecho algunas 73. También dio un curso de verano en la Academie de Droit Internacional de La
Haya.

Revista de Ciencias Sociales - Número 62 (2013) - Universidad de Valparáíso - ISSN 0716-7725-Valparaíso, Chile 
gestiones (...) para conseguir el visado, pero creía que carecía de expectativas de conseguirlo". Inopinadamente recibió la visita de un administrativo de la Facultad quien le informó que, por ser miembro del partido nazi, tenía buenos contactos en la policía local y que podía conseguirle el visado. La sorpresa de Kelsen fue tanto mayor cuando, al recibir el visado, la persona que se lo había conseguido no aceptó ninguna recompensa económica. Kelsen había pensado al principio que le exigiría una buena cantidad de dinero, como cabía esperar. "Así fue "concluye Kelsen - cómo aquel nazi, desinteresadamente, me salvó la vida. Nunca llegué a saber su nombre"74.

Durante los años de Colonia Kelsen continuó su actividad publicista, siendo de destacar su estudio "Quién debe ser el guardián de la Constitución?"75, además de otros, sobre todo de Derecho internacional. ${ }^{76}$ También en estos años aparecen varios trabajos suyos sobre Platón ${ }^{77}$ — por el que Kelsen siempre sintió un especial interésy sobre Aristóteles ${ }^{78}$.

En 1933 se publica en España la primera versión de la Teoría pura del Derecho ${ }^{79}$. Este es un hecho sorprendente, ya que la primera

74. Hans Kelsen im Selbszeugnis, cit., p. 83.

75. Hans Kelsen, "Wer soll der Hüter der Verfassung sein?” Die Justiz. Monatschrift für Erneuerung des Deutschen Rechtswesens. Zugleich Organ des Republikanischen Richterbundes, Volumen 6, 1931, pp. 576-628.

76. Destaca Hans Kelsen, "Théorie générale du droit internacional. Problèmes choisis”, Académie de droit internacional, Recueil des cours, volumen 42, 1932, pp. 116-351.

77. Hans Kelsen, "Die platonische Gerechtigkeit”. Kant-Studien. Philosophische Zeitschrift, Tomo 38, 1933, pp. 91-117. "Die platonische Liebe”. Imago. Zeitschrift für psychoanalitische Psichologie, ihre Grenzgebiete und Anwendung, volumen 19, 1933, pp. 34-98, 225-255.

78. Hans Kelsen, "Die hellenisch-makedonische Politik und die "Politik" des Aristoteles”. Zeitschrift für öffentliches Recht, volumen 13, 1933, pp. 625-678.

79. Hans Kelsen, La Teoría Pura del Derecho (Método y Conceptos Fundamentales), versión del alemán por Luis Legaz y Lacambra, Editorial Revista de Derecho

Facultad de Derecho y Ciencias Sociales - Universidad de Valparaíso - Chile 
edición en alemán de la obra principal de Hans Kelsen se publicará en 1934. Como se explicará en las páginas que siguen, esta obra tiene en español cuatro ediciones, mientras que en alemán sólo fueron dos las que se publicaron.

\section{Ginebra. Praga}

Kelsen relata en su "Autobiografía" que de Colonia se fue primero a Viena, con la intención de poder orientar desde esta ciudad su próximo futuro. "Que la Universidad de Viena no hizo nada en absoluto para posibilitarme la continuación de mi actividad académica, es algo que se entiende por sí mismo", habida cuenta de la situación política. En contraste con esto, Kelsen recibió tres ofertas: de la London School of Economics, de la New School of Social Research de Nueva York y del Institut Universitaire de Hautes Études internacionales de Ginebra. Se decidió por esta última, sobre todo porque, según sus propias palabras, su dominio del francés — aunque lejos de ser perfecto- era muy superior al de la lengua inglesa. Además, las condiciones externas de trabajo en Ginebra era excelentes: tan sólo dos clases y un seminario a la semana. El sueldo, subraya Kelsen, no era tan bueno como el de Colonia, pero suficiente para vivir con comodidad. Lo mejor de Ginebra era que iba a disponer de mucho tiempo para el trabajo científico.

En 1934 ve la luz la primera edición de la que puede considerarse la obra más famosa y leída de Hans Kelsen: Reine Rechtslehre-Teoría pura del Derecho ${ }^{80}$. A los aspectos temáticos y al enfoque de esta obra va dedicado el siguiente epígrafe de este estudio.

Privado, Madrid 1933. En la primera página del libro se cambia algo el título de la obra que aparece en la portada: "El Método y los Conceptos Fundamentales de la Teoría Pura del Derecho". Escribe Legaz en el "Prólogo del traductor": "Debo gratitud al gran maestro - mi maestro- y amigo el profesor Hans Kelsen por haberme dado ocasión de asociar mi nombre al suyo, brindándome la traducción de este precioso trabajo, inédito en alemán, en el que se exponen las líneas fundamentales de la teoría pura del Derecho". (p. 1).

80. Hans Kelsen, Reine Rechtslehre. Einleitung in die rechtswissenschaftliche Problematik, Franz Deuticke, Leipzig und Wien, 1934. El Prólogo está firmado por Hans Kelsen en Ginebra en mayo de 1934. El libro de esta edición primera en

Revista de Ciencias Sociales - Número 62 (2013) - Universidad de Valparáíso - ISSN 0716-7725-Valparáiso, Chile 
Kelsen centró entonces su actividad investigadora en un asunto que le atraía sobremanera desde los tiempos de Viena y que sería objeto de publicación de varias obras de antropología. Se había propuesto en un principio hacer la historia del Derecho natural pero pronto descubrió, al estudiar a los griegos, su conexión con las creencias religiosas y más en concreto con las animistas. Encontró abundante material en los escritos de Edgard Burnett Tylor (1832-1917) ${ }^{81}$, de James George Frazer (1854-1941) ${ }^{82}$ y de Lucien Lévy-Bruhl (1857-1939) ${ }^{83}$. Comenta Kelsen que "estos sabios, al igual que casi todos los etnólogos, consideraban tan sólo como supersticiones a las creencias primitivas sobre el alma, sin ver en ellas sus funciones eminentemente sociales". Asimismo, Kelsen veía errónea la tesis principal del llamado "pre-animismo", que considera las ideas primitivas tienen su explicación en la magia entendida como algo desligado del animismo. Durante 12 años había trabajado Kelsen en este asunto y para 1939 puso en manos de una editorial holandesa su libro Vergeltung und Kausalität ("Retribución y Causalidad") que, sin embargo, no se publicaría hasta 1946, pasada la Segunda Guerra Mundial ${ }^{84}$. Entre tanto, había visto la luz en 1943 una

alemán tiene 236 páginas, de las cuales 154 son de texto, y las restantes se dedican, primero, a la "Bibliografía de la Teoría pura del Derecho" — elaborada por Rudolf A. Métall-, que contiene tanto los "escritos teórico-jurídicos de Hans Kelsen” como los "trabajos de otros autores en referencia a la teoría pura del derecho", y en segundo lugar un índice de materias. La última edición, sin la bibliografía mencionada, es: Hans Kelsen, Reine Rechtslehre. Einleitung in die rechtswissenschaftliche Problematik, Studienausgabe der 1. Auflage 1934, herausgegeben und eingeleitet von Matthias Jestaedt, Mohr Siebeck, Tübingen 2008. Hay traducción española: Hans Kelsen, Teoría pura del derecho. Introducción a los problemas de la ciencia jurídica [Primera edición de 1934], Presentación de Gregorio Robles. Traducción de Gregorio Robles y Félix F. Sánchez, Editorial Trotta, Madrid 2011.

81. Su libro más importante es: Edgard B. Tylor, Anthropology: An introduction to the study of man and civilization, London 1881.

82. James G. Frazer, The Goleen Bough, $1^{\text {a }}$ ed. London 1890; $2^{\text {a }}$ ed. London 1900; $3^{\mathrm{a}}$ ed. London 1907-1915, en 12 volúmenes.

83. Lucien Lévy-Bruhl, La mentalité primitive, Paris 1922; L'âme primitive, Paris 1927.

84. Hans Kelsen, Vergeltung und Kausalität, Eine soziologische Untersuchung, W.P. van Stockum, The Hague \& The University of Chicago Press, Chicago, 1941.

Facultad de Derecho y Ciencias Sociales - Universidad de Valparaíso - Chile 
versión algo diferente en inglés con el título Society and Nature ${ }^{85}$. Para esos años Kelsen ya se encontraba en EEUU. Pero no nos adelantemos a los acontecimientos y volvamos al período de los años treinta.

Durante los años de Ginebra Hans Kelsen obtuvo el doctorado honoris causa por la Universidad de Harvard y por la de Utrecht. Eso ocurría en el año 1936. También tuvo lugar su "corta y no muy feliz actividad en la Universidad alemana de Praga" ${ }^{86}$. En su "Autobiografía" relata con bastante detalle los problemas con los que se encontró en esta Universidad. Su intención era compatibilizar la enseñanza en Ginebra con la de Praga, un semestre en la primera ciudad y otro semestre en la segunda. Kelsen tenía interés por Praga en cuanto que con ello podía conseguir una pensión de jubilación para un futuro que no se aventuraba ya muy lejano: piénsese que cuando comienza su actividad en Praga, en 1936, contaba 55 años y su futuro económico seguía siendo incierto. Pero, intuyendo las dificultades, no quería abandonar Ginebra bajo ningún concepto. Marchó solo a la bella ciudad checa, al principio vivió en hoteles y después, subalquilado en un apartamento. En Praga los estudiantes nacionalistas alemanes le hicieron la vida imposible desde el primer día. Kelsen tenía que ir a sus clases, con muy escasos alumnos, acompañado por dos policías, uno se sentaba en la primera fila y el otro, en la última. Exclama Kelsen, irónicamente dolorido: "iUna imagen grotesca de la libertad académica!" ${ }^{87}$. Además, recibía amenazas de muerte con cierta frecuencia. Ante la presión de los nacionalistas y la muerte por atentado de uno de sus amigos, el profesor Theodor Lessing, decidió abandonar Praga. La viuda de Lessing le había advertido a Kelsen para que se

A consecuencia de las circunstancias políticas, este libro, que fue impreso en el año 1940, sólo vería la luz en 1946.

85. Hans Kelsen, Society and Nature. A Sociological Inquiry, The University of the Chicago Press, Chicago 1943. Traducción al español por Jaime Perriaux: Hans Kelsen, Sociedad y Naturaleza. Una investigación sociológica, Depalma, Buenos Aires 1945.

86. Hans Kelsen im Selbszeugnis, citado, p. 87.

87. Hans Kelsen im Seblszeugnis, citado, p. 89.

Revista de Ciencias Sociales - Número 62 (2013) - Universidad de Valparáíso - ISSN 0716-7725-Valparáiso, Chile 
tomara las amenazas en serio. Su marido no se las había tomado así, y el resultado estaba a la vista. Su actividad en Praga había durado poco: desde octubre de 1936 hasta febrero o marzo de 1938.

\section{La primera edición de Reine Rechtslehre}

La primera edición de Reine Rechtslehre (1934) viene a ser un breve compendio del pensamiento jurídico de Hans Kelsen, al cual había precedido un trabajo previo de múltiples publicaciones y de debates en el seno de su seminario privado. En este libro se recogen en sustancia todos los componentes de la Teoría pura del Derecho. Kelsen concibe esta teoría como una auténtica Teoría general del Derecho, en rigor la única posible para los juristas. Se caracteriza por ser una teoría positivista, y dentro de ella, por su formalismo y por su normativismo. Para Kelsen la Teoría pura del Derecho no pretende otra cosa que ser una "geometría del fenómeno jurídico", y al igual que la geometría su objeto son las formas, en este caso las formas jurídicas. Ahora bien, esas formas sólo son investigables a partir de la forma jurídica básica, que es la norma de Derecho. De ahí que el formalismo y el normativismo sean como las dos caras de una misma moneda. A la vez el Derecho, para la Teoría pura, es simplemente el Derecho positivo, "puesto" por los hombres en la sociedad.

La Teoría pura del Derecho se manifiesta en dos aspectos, vinculados pero diferentes: Por una parte, es crítica de las teorías jurídicas tradicionales. Por otra, es constructiva de sus propias concepciones. En el aspecto crítico su objetivo es depurar a la Ciencia del Derecho de todos los elementos extrajurídicos — de ahí el calificativo de "pura"-, en especial de los de naturaleza sociológica y psicológica y de los de naturaleza ideológica (crítica del Derecho natural, como manifestación de ideologías políticas). En el aspecto constructivo, se centra en la elaboración de todos los conceptos jurídicos formales a partir del concepto de norma o proposición jurídica (Rechtssatz).

La norma o proposición jurídica es — para Kelsen- un juicio hipotético que conecta un supuesto de hecho - en especial, un hecho ilícito- y una consecuencia jurídica —en especial, una sanción- por medio de un nexo de deber (sollen). En este concepto Kelsen no se

Facultad de Derecho y Ciencias Sociales - Universidad de Valparaíso - Chile 
separa de lo que puede ser un lugar común en la teoría jurídica del positivismo de la época, siendo evidente la influencia de autores como Binding, Thon o Bierling. El método, por tanto, es el normativista. Consiste en extraer, de modo directo o indirecto, del concepto de norma o proposición jurídica todos los demás conceptos jurídicos formales, los cuales por ser formales son universales, esto es, son conceptos aplicables a todo Derecho positivo.

A partir del concepto de norma jurídica se analizan los demás. El ilícito es el supuesto de hecho de la norma. El deber jurídico es el que tiene el órgano de aplicar la norma; dicho deber implica un deber jurídico secundario dirigido a los destinatarios de la norma para que no realicen el supuesto fáctico, esto es, para que no cometan un ilícito. La sanción es el segundo elemento de la norma y consiste en la privación de un bien jurídico. La sanción se imputa al acto ilícito e indirectamente a una persona responsable de dicho acto - ya sea la misma persona que lo ha realizado u otra que señale el derecho. El derecho subjetivo es la posibilidad que concede el orden jurídico para conseguir que el sujeto del deber jurídico lo cumpla. Persona es una construcción unitaria de un conjunto de normas, conjunto al que se imputan actos, responsabilidades y sanciones. El Estado es el orden jurídico mismo.

Todos estos conceptos conforman la denominada estática jurídica. La dinámica jurídica se ocupa de la creación y aplicación del derecho. Conecta con la teoría de la estructura escalonada del ordenamiento jurídico (Stufenbautheorie), según la cual las normas están organizadas en el ordenamiento jurídico de acuerdo a una jerarquía. El Derecho positivo tiene su norma superior en la constitución, la cual se ve concretada en las leyes, éstas a su vez en los reglamentos y demás normas de la administración. Junto a estas normas de carácter general, en un escalón inferior se sitúan las normas individualizadas, tales como las sentencias los jueces (la jurisprudencia), los actos administrativos y los negocios jurídicos de los particulares. Por fin, la base de la construcción escalonada la forman los actos de aplicación o ejecución de las normas.

A la pregunta de por qué es válida una determinada norma, se contesta: porque deriva su validez de una norma superior. Al llegar a la constitución, esta pregunta también tiene su respuesta. Lo único que ocurre, es que no es una respuesta que proporcione el Derecho positivo,

Revista de Ciencias Sociales - Número 62 (2013) - Universidad de Valparáíso - ISSN 0716-7725-Valparaíso, Chile 
sino el pensamiento jurídico. La respuesta es ésta: la constitución es válida porque se supone su validez, esto es, su obligatoriedad jurídica. Dicho en otras palabras: la constitución es válida porque parte del supuesto o hipótesis de que hay una norma no "puesta" — no positivaque dice que es obligatorio obedecer la constitución. A esa norma se la denomina norma fundamental o fundante (Grundnorm).

Parte importante de la obra se dedica a "deconstruir" los llamados dualismos jurídicos que, para Kelsen, constituyen por lo general una expresión más o menos solapada de posturas iusnaturalistas. Empezado por el dualismo Derecho natural y Derecho positivo, ataca también la distinción entre Derecho público y privado, Derecho objetivo y subjetivo, Estado y Derecho, Derecho estatal y Derecho internacional.

Por último, sostiene una teoría de la interpretación según la cual la norma es un marco abierto a distintas posibilidades interpretativas, todas las cuales serían "correctas”. Entre ellas, el juez —y, en general, el órgano aplicador - elige una. La decisión no puede fundamentarse científicamente, y por ese motivo Kelsen sostiene que tiene carácter "irracional". No quiere decir, obviamente, que la decisión no pueda ser razonable; sino, simplemente, que no se ajusta a la racionalidad científica. Por su parte, la Ciencia del Derecho tiene como objetivo exponer descriptivamente las diversas alternativas interpretativas de las normas jurídicas.

De esta primera edición de Reine Rechtslehre se publicó una versión en español en $1941^{88}$, versión que —a pesar de ser manifiestamente mejorable - ha conocido varias reimpresiones. Recientemente, a instancias de la Editorial Trotta, aceptamos la tarea de una nueva traducción, que vio la luz en $2011^{89}$.

88. Hans Kelsen, La Teoría Pura del Derecho. Introducción a la problemática científica del derecho. Traducción de Jorge García Tejerina. Introducción de Carlos Cossio. Editorial Losada, Buenos Aires 1941.

89. Hans Kelsen, Teoría pura del derecho. Introducción a los problemas de la ciencia jurídica, ya citada.

Facultad de Derecho y Ciencias Sociales - Universidad de Valparaíso - Chile 


\section{Berkeley}

Relata Kelsen que muy pronto se convenció que una guerra era inminente. Pensó que, al no encontrar la Alemania de Hitler ningún obstáculo serio para anexionarse Austria ni para invadir los Sudetes, pronto se extendería su acción en otras direcciones. Cuando en 1939 estalló la guerra, Kelsen estaba convencido de que el ejército alemán invadiría Suiza. En esto se equivocó, pero gracias a esa equivocación lograría hallar un sitio definitivo para su trabajo y para su vida y la de su familia. A finales de mayo de 1940 abandonaron Ginebra rumbo a los Estados Unidos de Norteamérica. No fue una decisión fácil. Por una parte, Kelsen se encontraba cómodo en Ginebra. Por otra, su manejo del inglés estaba lejos de ser perfecto. Como él mismo señala, podía leer libros en lengua inglesa, pero no hablarla ni mucho menos escribir en inglés. Téngase en cuenta además que Kelsen tenía entonces casi 60 años.

Llegaron a Nueva York a comienzos del verano de 1940. Al principio estuvo adscrito a la New School of Social Research. Kelsen creía que, al ser doctor honoris causa por la Universidad de Harvard, se le abrirían las puertas en ella. No fue así. Tan sólo pudo impartir docencia allí durante un par de años. El sueldo no se lo pagaba la Universidad sino una Fundación. Al concluir el año, no le prorrogaron la docencia, con el pretexto de que no podían hacerle permanente. Kelsen se sintió profundamente decepcionado. Señala: "El presidente [de la Universidad de Harvard] rechazó la posibilidad de prolongar mi encargo un tercer año, aunque mi sueldo lo pagase una fundación; fundamentó este rechazo en que una prolongación envolvía una obligación moral de la Universidad de tenerme permanentemente y que no había una cátedra libre que se me pudiera adscribir. Dudo de que fuera éste el verdadero motivo. Este fiasco me humilló sobremanera, toda vez que, en cuanto doctor honoris causa de la Universidad de Harvard, había esperado un trato mejor" ${ }^{" 90}$.

En 1942 Hans Kelsen recibió una invitación de un año como visiting professor por parte de la Universidad de Berkeley (California).

90. Hans Kelsen im Selbstzeugnis, citado, p. 93. El presidente de la Universidad de Harvard de 1933 a 1953 fue James Bryant Conant (1893-1978).

Revista de Ciencias Sociales - Número 62 (2013) - Universidad de Valparáíso - ISSN 0716-7725-Valparaíso, Chile 
Fue en esta Universidad, y en concreto en el departamento de Ciencia política, donde Kelsen encontró un puesto definitivo hasta su jubilación. Su cátedra se denominó "Internacional law, jurisprudence, and origin of legal institutions", "Derecho internacional, Teoría general del Derecho, y Orígenes de las instituciones jurídicas”. En 1945 se le nombró catedrático ordinario y estabilizó así su situación definitivamente. A la sazón Kelsen contaba con 64 años. En esos años, por primera vez en su vida, llegó a ser propietario de una casa.

En 1945 ve la luz su obra General Theory of Law and State ${ }^{91}$ -“Teoría general del Derecho y del Estado”. Este libro es una versión actualizada del pensamiento jurídico de Kelsen, con la que pretende además entrar en diálogo con la bibliografía en inglés, adaptándola lo más posible a la mentalidad norteamericana. Así puede comprobarse por los autores que cita mayoritariamente ${ }^{92}$. También se ratifica esto por las propias palabras de Kelsen: "El presente libro tiene por objeto formular nuevamente, más bien que volver a publicar, pensamientos e ideas anteriormente expuestos en alemán y en francés" ${ }^{93}$. Y continúa: "El propósito ha sido doble: en primer término, presentar los elementos esenciales de lo que el autor ha denominado la 'Teoría pura del Derecho', en forma tal que esos elementos resulten más accesibles a quienes se

91. Hans Kelsen, General Theory of Law and State, traducción al inglés de Anders Wedberg, $20^{\text {th }}$ Century Legal Philosophy Series, vol. 1, Harvard University Press, Harvard (Mass.), 1945. Versión española: Hans Kelsen, Teoría general del Derecho y del Estado, traducción de Eduardo García Máynez, Imprenta Universitaria, México DF, 1950 .

92. Blackstone, Roscoe Pound, Thomas E. Holland, Eugen Ehrlich (autriaco; pero Kelsen cita su obra de sociología jurídica traducida al inglés), N.S. Timasheff, L. Petrazisky, J. Austin, J. Hall, John Ch. Gray, Kart N. Llewellyn, Joseph W. Bingham, T.H. Huxley, W.A. Robson, O.W. Colmes, B.N. Cardozo, John C.H. Wu, W.W. Willoughby, L. Oppenheim, A.S. Hershey, A. Nussbaum, F.J. Goodonow, J.W. Garner, H.J. Ford, A. Esmein, Brougham, A.R. Radcliffe-Brown, Coleman Phillipson, W. Ballis. Las obras citadas en lengua alemana (Savigny, Weber, Strisower, etc.) son escasas.

93. En nota a pie de página se refiere a estas tres obras suyas: Allgemeine Staatslehre (1925); Théorie Générale du Droit Internacional Public (1928); Reine Rechtslehre (1934).

Facultad de Derecho y Ciencias Sociales - Universidad de Valparaíso - Chile 
han educado en las tradiciones y atmósfera del Common Law; en segundo lugar, dar a tal Teoría una formulación que la haga capaz de abarcar tanto los problemas e instituciones de los derechos inglés y norteamericano, como los de los países de derecho escrito, para los que fue originariamente formulada. El autor confía en que esta nueva formulación haya podido traducirse en un perfeccionamiento" 94 .

Resume así sus impresiones en su "Autobiografía”, escrita como sabemos dos años después, en 1947. "Mi actividad docente es bastante satisfactoria. Con mi Teoría pura del Derecho encajaría mejor en una Facultad de Derecho. Pero las escuelas de Derecho americanas no tienen interés alguno en la Teoría del Derecho desarrollada científicamente. Son training schools —escuelas para el entrenamiento del oficio jurídico; su función es preparar para la profesión práctica de abogado. En ellas se enseña, casi exclusivamente, Derecho americano, y ello de acuerdo con el case method. Los tribunales americanos motivan sus decisiones básicamente teniendo en cuenta los precedentes, por eso es comprensible que las escuelas de Derecho consideren que su finalidad docente sea familiarizar a los estudiantes con el mayor número posible de cases. Con toda seguridad, un estudiante americano está mejor preparado para el ejercicio de la abogacía que un jurista alemán o austriaco al finalizar sus estudios de Derecho en la Universidad. El Derecho, como objeto de conocimiento científico encaja quizás mejor en una Facultad de Filosofía, de Historia o de Ciencias sociales. Lo que echo de menos aquí, en el departamento de Ciencia política, es que entre los estudiantes (...) no haya interés alguno en el trabajo científico. Se preparan muy a conciencia para los exámenes y realizan excelente trabajos de seminario. Pero durante todos estos años no he encontrado a ninguno que quisiera especializarse en el campo de la Jurisprudencia (Teoría del Derecho) o del Derecho internacional. Esto también se vincula al hecho de que estas materias en el political science department son asignaturas secundarias, de modo que quien se decide por la carrera académica elige preferentemente otras disciplinas para realizar su doctorado. Así las cosas, la actividad docente me deja tiempo para el trabajo científico.

94. Hans Kelsen, Teoría general del Derecho y del Estado, trad. de E. García Máynez, citado, p. V.

Revista de Ciencias Sociales - Número 62 (2013) - Universidad de Valparáíso - ISSN 0716-7725-Valparaíso, Chile 
La biblioteca de la Universidad es espléndida, y tanto el clima como el medio no dejan nada que desear. En Berkeley he comprado una casita con jardín; en él florecen las rosas, lo que me produce un gran contento" 95 .

Durante los años siguientes hasta su muerte Hans Kelsen recibió numerosas distinciones y honores. Eso no impidió que continuara su incansable labor científica.

En 1950 publica su The Law of the United Nations ${ }^{96}$ y, poco después, en 1952, su tratado de derecho internacional: Principles of International Law ${ }^{97}$.

En el prefacio de esta obra destaca Kelsen que si bien es usual dividir la materia del Derecho internacional en dos partes —el Derecho de paz y el Derecho de guerra-, a la vista de la nueva situación después del pacto Kellogg-Briand y de la Carta de las Naciones Unidas, "la guerra sólo puede considerarse lícita si es una reacción contra una violación del Derecho internacional”. Por esta razón, el llamado Derecho de guerra lo introduce sistemáticamente en el marco de las sanciones previstas por el Derecho internacional. En este libro Kelsen vuelve a destacar que su método es el jurídico, y no el político: "Pareciera ser un pleonasmo vano afirmar que una obra de Derecho internacional sólo se ocupa de los problemas concernientes desde un punto de vista jurídico, es decir, legal. Si el Derecho internacional es Derecho en el verdadero sentido del término - y esto se da por sentado en este libro- ¿qué otro método sino el jurídico podría ser aplicado en la descripción y explicación de este objeto? Si, a pesar de ello, creo necesario subrayar el

95. Hans Kelsen im Selbstzeugnis, p. 94.

96. Hans Kelsen, The Law of the United Nations. A Critical Analysis of Its Fundamental Problems. Published under the auspices of the London Institute of World Affairs. London (Stevens \& Sons); New York (Frederick A. Praeger Inc.), 1950.

97. Hans Kelsen, Principles of Internacional Law, Rinehart \& Co, New York 1952. Versión en español: Hans Kelsen, Principios de derecho internacional público, traducción por Hugo Caminos y Ernesto C. Hermida, El Ateneo, Buenos Aires et alt., 1965.

Facultad de Derecho y Ciencias Sociales - Universidad de Valparaíso - Chile 
carácter puramente jurídico de este libro, lo hago en oposición a una tendencia difundida entre los autores de Derecho internacional quienes — si bien no se atreven a negar el carácter legal y por lo tanto la fuerza obligatoria de este orden social- propugnan como adecuado un enfoque diferente al jurídico, especialmente, el enfoque político. En mi opinión, este criterio no es otra cosa que un intento de justificar la no aplicación del Derecho existente en caso de que éste se halle en conflicto con algún interés o más bien con lo que el respectivo autor considera ser el interés de su Estado" ${ }^{98}$.

En 1960 ve la luz la segunda edición de Reine Rechtslehre ${ }^{99}$ -Teoría pura del Derecho. El libro contiene también un "Apéndice" sobre "El problema de la justicia", así como un índice de materias y de nombres, y una lista ordenada cronológicamente de las publicaciones de Hans Kelsen, elaborada por Rudolf A. Métall.

Esta segunda edición difiere de la primera notablemente, no sólo en extensión sino asimismo en contenidos. Es bastante más voluminosa y compleja. Los principios básicos se mantienen: positivismo, formalismo, normativismo, separación de sein y sollen, jerarquía de las normas, etc. Pero en el detalle del análisis las diferencias se muestran importantes.

En vano se buscará en la segunda edición un concepto, expresamente formulado, de la norma jurídica, como se hacía en la primera edición. Kelsen tan sólo define ahora el concepto genérico de norma: "Con la palabra 'norma' se designa que algo debe ser o suceder, en especial, que una persona debe comportarse de determinada manera” ${ }^{100}$.

98. Hans Kelsen, Principios de derecho internacional público, trad. esp., cit., pp. XI-XII.

99. Hans Kelsen, Reine Rechtslehre. Mit einem Anhang: Das Problem der Gerechtigkeit. Zweite, vollständig neu bearbeitete und erweiterte Auflage, Verlag Franz Deuticke, Wien 1960. Traducción al español de Roberto J. Vernengo, Presentación de Rolando Tamayo y Salmorán, UNAM, México DF, 1979. Esta versión en español contiene únicamente el texto principal.

100. Hans Kelsen, Reine Rechtslehre, cit., p. 4.

Revista de Ciencias Sociales - Número 62 (2013) - Universidad de Valparáíso - ISSN 0716-7725-Valparaíso, Chile 
Aunque se mantiene la dualidad entre ser y deber ser, y se sostiene que el deber ser es lo que define cualquier tipo de norma, también de la norma jurídica, se entra en la diferenciación de los diversos tipos de normas, caracterizados cada uno de ellos por un verbo modal: sollen (deber), pero también können (poder) y dürfen (estar permitido). Se completa la teoría de las normas jurídicas con la diferenciación entre normas jurídicas completas o independientes (selbständige Rechtsnormen) y normas jurídicas incompletas o dependientes (unselbständige Rechtsnormen). El tratamiento de los conceptos jurídicos es más profundo y en algunos aspectos diferente. Me referiré aquí únicamente a dos ejemplos. Si en la primera edición la eficacia es condición de la validez de un orden jurídico, pero no de una norma individualmente considerada, en la segunda edición la eficacia se erige en condición tanto de la validez del orden jurídico en su conjunto como de la norma concreta. Esto representa, puede decirse, un cierto acercamiento al realismo jurídico - propio de los juristas estadounidenses - y, por tanto, al sociologismo. El derecho subjetivo experimenta un tratamiento más profundo que en la primera edición y adquiere una entidad propia. En esta segunda edición se profundiza asimismo en la teoría de la norma fundamental. Por lo demás, es el propio Kelsen el que señala las diferencias entre la segunda y la primera edición siempre que le perecen relevantes.

En 1971, con motivo del nonagésimo aniversario de Hans Kelsen se funda en Viena el "Instituto Hans Kelsen", con el objeto de expandir y continuar la obra del gran jurista, contribuyendo así al desarrollo de los estudios jurídicos, y muy en especial, de la Teoría del Derecho.

Kelsen murió en Berkeley el 19 de abril de 1973. Su esposa, Margarete, había fallecido a comienzos de ese mismo año.

Tras la muerte de Kelsen se han publicado tres importantes obras de su autoría: Allgemeine Theorie der Normen ${ }^{101}$ — "Teoría general de

101. Hans Kelsen, Allgemeine Theorie der Normen. Im Auftrag des Hans KelsenInstituts aus dem Nachlass herausgegeben von Kurt Ringhofer und Robert Walter, Manz, Wien 1979. Traducción al español de Hugo Carlos Delory Jacobs. Introducción de Juan Federico Arriola, Ed. Trillas, México 1994.

Facultad de Derecho y Ciencias Sociales - Universidad de Valparaíso - Chile 
las normas"-, Die Illusion der Gerechtigkeit ${ }^{102}$ — "La ilusión de la justicia”-, y Secular Religion"103 — "Religión secular".

Para la Teoría del Derecho es especialmente significativa su obra sobre las normas. Está inacabada, de tal modo que las conclusiones que se puedan extraer de su lectura pueden estar bajo la duda de si el autor habría dejado el texto tal como quedó a su muerte. Esta obra tiene la peculiaridad de que, de todos los libros de Kelsen, es con mucho el que muestra más notas aclaratorias ${ }^{104}$. Consta de 61 capítulos, casi todos breves, que pueden ser divididos — aunque en el índice no figura esta división - en tres grandes apartados: el primero, que ocuparía los 37 primeros capítulos, podría titularse "teoría de la norma" (no de la norma jurídica, en general, sino de la norma a secas); el segundo abarcaría los capítulos 38 a 49 y podría llevar el título de "norma y enunciado"; por último, el tercer apartado estaría dedicado - para negarla- a la "lógica de las normas" e integraría los capítulos 50 a 61. Obsérvese que en esta obra Kelsen no aborda una teoría de las normas del Derecho sino una teoría general de las normas, y en concreto se refiere a tres tipos de normas: las del Derecho, las de la Moral y las de la Lógica.

102. Hans Kelsen, Die Illusion der Gerechtigkeit. Eine kritische Untersuchung der Sozialphilosophie Platons. Im Auftrag des Hans Kelsen-Instituts aus dem Nachlass herausgegeben von Kurt Ringhofer und Robert Walter, Manz, Wien 1985.

103. Hans Kelsen, Secular Religion. A Polemic against the Misinterpretation of Modern Social Philosophy, Science and Politics as 'New Religions'. Springer, Wien/New York, 2012.

104. Nada menos que las últimas 142 páginas, de las 362 que tiene el libro, están dedicadas íntegramente a las notas. En ellas se recoge abundante bibliografía, así como citas de otros autores y comentarios del propio Kelsen.

Revista de Ciencias Sociales - Número 62 (2013) - Universidad de Valparáíso - ISSN 0716-7725-Valparaíso, Chile 